Portland State University

PDXScholar

$12-27-2000$

\title{
Black Women's Health: a Content Analysis of the Journal of the American Medical Association, the American Journal of Public Health, and the New England Journal of Medicine (1989-1998)
}

Tonia Marie Burkett

Portland State University

Follow this and additional works at: https://pdxscholar.library.pdx.edu/open_access_etds

Part of the Inequality and Stratification Commons, and the Medicine and Health Commons Let us know how access to this document benefits you.

\section{Recommended Citation}

Burkett, Tonia Marie, "Black Women's Health: a Content Analysis of the Journal of the American Medical Association, the American Journal of Public Health, and the New England Journal of Medicine (1989-1998)" (2000). Dissertations and Theses. Paper 3042.

https://doi.org/10.15760/etd.3037

This Thesis is brought to you for free and open access. It has been accepted for inclusion in Dissertations and Theses by an authorized administrator of PDXScholar. Please contact us if we can make this document more accessible: pdxscholar@pdx.edu. 
THESIS APPROVAL

The abstract and thesis of Tonia Marie Burkett for the Master of Science in Sociology were presented December 27, 2000, and accepted by the thesis committee and the department.

COMMITTEE APPROVALS :
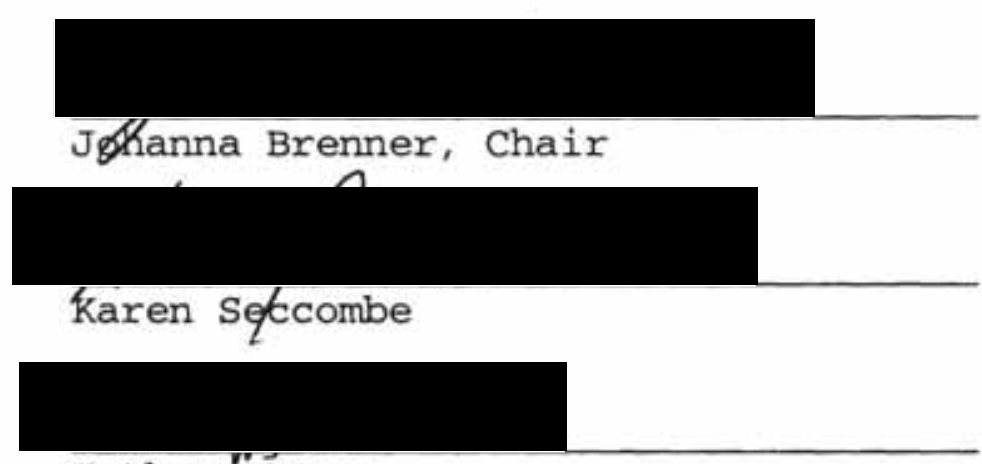

Kathryn Farr

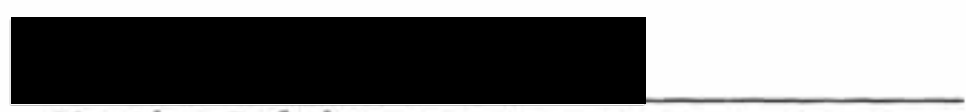

Martha Balshem

Representative of the office of Graduate Studies

DEPARTMENT APPROVAL:

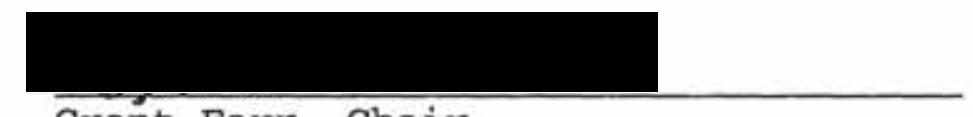

Grant Farr, Chair

Department of Sociology 


\section{ABSTRACT}

An abstract of the thesis of Tonia Marie Burkett for the Master of Science in Sociology presented December 27, 2000

Title: Black Women's Health: A Content Analysis of the Journal of the American Medical Association, the American Journal of Public Health, and the New England Journal of Medicine (1989-1998).

According to the National Vital Statistics Report (1998), Black women age 45-64 are ten times more likely than white women of the same age to die from diseases of the heart. They are five times more likely to die from diabetes. The goal of this study was to examine how articles published in leading medical journals between 1989 and 1998 accounted for such differences in health outcomes among Black and white women.

The explanatory content of the articles was analyzed and coded according to four types of attributions: genetic/biological, cultural/behavioral, structural/socioeconomic and alternative. Each type of 
explanation derives from different assumptions and operates with different models for understanding why health outcomes vary among groups. Alternative explanations are those that focus on the direct effect of race/gender oppression on Black women's health. Genetic/biological attributions occurred less frequently than structural/socioeconomic and cultural behavioral but were more likely to occur than alternative attributions, which were the least often employed. While alternative attributions are considered in some of the articles about Black women's health and mortality, they are overall rarely employed. The finding that explanations that most directly explore the impact of racism and sexism on Black women's health occur least often has important implications. Articles published in these three journals inform medical practitioners and affect the ability of such practitioners to adequately address the needs of Black women in their care. 


\section{BLACK WOMEN'S HEALTH: A CONTENT ANALYSIS}

OF THE JOURNAL OF THE AMERICAN MEDICAL ASSOCIATION, THE AMERICAN JOURNAL OF PUBLIC HEALTH, AND THE NEW ENGLAND JOURNAL OF MEDICINE (1989-1998)

by

TONIA MARIE BURKETT

A thesis submitted in partial fulfillment of the requirements for the degree of

MASTER OF SCIENCE

in

SOCIOLOGY

Portland State University

2003 


\section{DEDICATIONS}

I dedicate this thesis to my mother, Janet Shepherd, who encouraged me to do my best. Her enduring faith and unconditional love encouraged me to keep working towards achieving my goals.

I also dedicate this thesis to "The Queens:" Janet Noakes; Penny Kennedy; Meg Kilmer; and Marla Via for their love and guidance. They supported my decision to return to school and have been a tremendous source of encouragement. I especially want to thank Janet Noakes, who has been there for me in both good and bad times during my graduate education. She is my Soul Mother and I love her for everything she is and has become in the years I have known her. 


\section{ACKNOWLEDGMENTS}

One of the most important lessons I have learned in the process of receiving a formal education is that I cannot do it alone. To become educated requires patience, guidance, love, understanding, and the exchange of ideas.

I have received all of this from my mentor, friend, and advisor Dr. Johanna Brenner. Without her guidance over the many years that I have known her both as an instructor and as a friend I could not have completed this thesis. I acknowledge Carol Holdt for her dedicated friendship to me. Her love and photographs of her cats and garden have kept me warm on cold days. I would also like to acknowledge the support of my good friend, Jackie Clark, who at times was the only good reason for me to stay in North Carolina. I feel blessed to have the love and friendship of her and her family (my North Carolina family). I also acknowledge Shelley Furst, Sarah Jane, and Jane and Julie Feinberg for all of the love and support they have given to me over the years. I have known them for most of my life and they have always been my family and my greatest cheerleaders.

Additionally, I acknowledge all the Portland State 
faculty who served on my committee; Dr. Kathryn Farr, Dr. Karen Seccombe, and Dr. Martha Balshem. They provided much needed assistance during the writing of this thesis. I thank the faculty at North Carolina State University who provided comments on my thesis: Dr. Maxine Thompson, Dr. Barbara Risman, Dr. Don Tomaskovic-Devey, Dr. Ron Czaja, and Dr. Michael Schwalbe. 


\section{TABLE OF CONTENTS}

\section{PAGE}

ACKNOWLEDGMENTS $\ldots \ldots \ldots \ldots \ldots \ldots \ldots \ldots$ ii

LIST OF TABLES $\ldots \ldots \ldots \ldots \ldots \ldots \ldots \ldots \ldots \ldots \ldots \ldots \ldots \ldots \ldots \ldots \ldots \ldots$

LIST OF FIGURES $\ldots \ldots \ldots \ldots \ldots \ldots \ldots \ldots \ldots \ldots \ldots \ldots \ldots \ldots \ldots$

LIST OF ABBREVIATIONS.................. CHAPTERS

I INTRODUCTION $\ldots \ldots \ldots \ldots \ldots \ldots \ldots \ldots \ldots \ldots$

I REVIEW OF THE LITERATURE........... 17

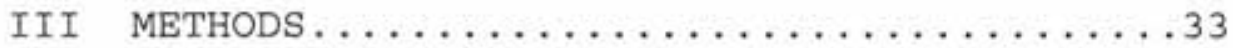

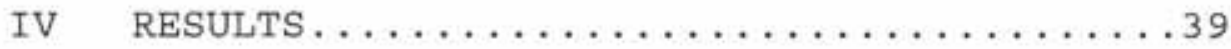

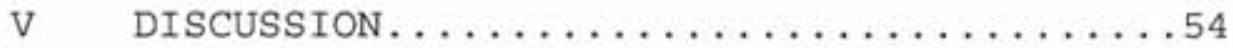

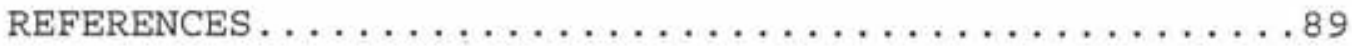
APPENDICES

A CODING CATEGORIES ................ 93

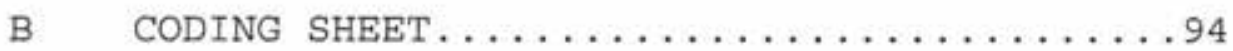

C NOTES.............................

D TOPIC CATEGORIES............... 97 


\section{LIST OF TABLES}

PAGE

Table 1. 1996 Death Rates..................72

Table 2. Breakdown of PubMed Search Process.......73

Table 3. Journal Articles by Topic......... . . . 74

Table 4. Study Population by Journal...........75

Table 5 . Attributions by Year.............

Table 6 . Attributions by Journal. . . . . . . . 77

Table 7. Attributions by Race/Sex.............78

Table 8. Attributions by Topic...............79

Table 9. Article Topics by Race/Sex.............80 


\section{LIST OF FIGURES}

PAGE

Figure 1. Models of Health and Mortality.........81

Figure 2. Alternative Model............... 82

Figure 3. Articles by Journal...............83

Figure 4. Articles by Topic.............. 84

Figure 5 . Articles by Race/Sex............... 85

Figure 6 . Attributions by Race/Sex...........86

Figure 7. Attributions by Journal ... . . . . . . 87

Figure 8 . Attributions by Year............ 88 


\section{LIST OF ABBREVIATIONS}

Journal of the American Medical Association....... JAMA The New England Journal of Medicine.............. The American Journal of Public Health.............. AJPH

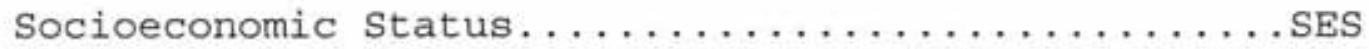
Sexually Transmitted Disease/Human Immunodeficiency

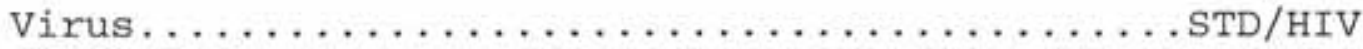
Coronary Heart Disease.................. CHD Cerebrovascular Disease.................. CVD Deterioration (disease, injury, aging).... Degenerative

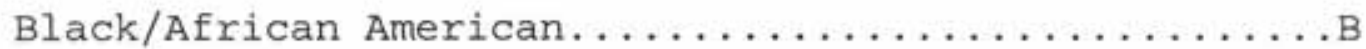

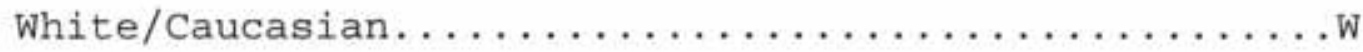

Other (Asian, Latino, Carribean, African).........

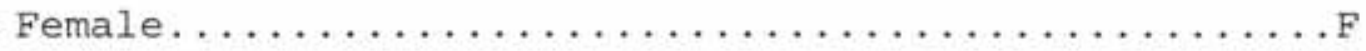

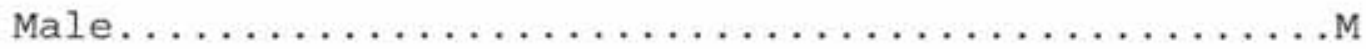
Coronary angioplasty bypass graft................ 
"Black Women's Health: A Content Analysis of the Journal of the American Medical Association, the American Journal of Public Health, and the New England Journal of Medicine (1989-1998)"

\section{CHAPTER I}

\section{INTRODUCTION}

Black women experience health problems and mortality at higher rates than white women (see Table 1). According to the National Vital Statistics Report (1998), Black women age 45 to 64 are ten times more likely than white women of the same age to die from heart diseases. They are five times more likely to die from diabetes. To what do medical researchers attribute these differences? The answers matter a great deal both for guiding further medical research and for improving the health of Black women.

This study was designed to examine how medical researchers account for the different health problems and mortality rates among whites and Blacks by examining articles in three medical journals: the American Journal of Public Health (AJPH), the Journal of the American Medical Association (JAMA), and the New England Journal of Medicine (NEJM). The attributions made within these journal articles were coded using models of disease 
described by Krieger and Bassett (1993) and Hummer (1996).

From the work of Krieger and Bassett (1993) and Hummer (1996) four types of explanations for health outcomes can be identified: genetic/biological, cultural/behavioral, structural/socioeconomic and alternative. Each type of explanation derives from different assumptions and operates with different models for understanding why health outcomes vary among groups.

These types of explanation frame the discussion of Black women's health in popular culture and media, as well as in professional arenas. Professional arenas include: medical textbooks, organization/ association newsletters, and scholarly journals. Articles in medical journals are written by professionals who research, practice, and teach medicine. Saint, and colleagues (2000) write:

Respondents reported spending 4.4 hours per week reading medical journal articles and reported reading only the abstract for $63 \%$ of the articles; these findings were similar for internists with and without epidemiology training. Respondents admitted to a reliance on journal editors to provide rigorous and useful information, given the limited time available for critical reading (881).

These journals are one of the leading sources of continuing education for medical practitioners. Attributions about differences in health and mortality 
for Blacks and whites are embedded in these articles and shape the practice of medicine and health services. They also become translated into more popular media and shape hegemonic cultural views of Black women and their health outcomes.

Some research on health discourses has indicated that health and mortality differences between Black women and other groups are often attributed to individual lifestyle and behaviors (Arfken and Houston 1996; Bennet 1991; Gates and McDonald 1997; Kumanyika and colleagues 1989; Shy 1997). The ideology of individualism implies that $\mathrm{Black}$ women make choices about the way they live and behave without regard for or knowledge of the consequences of those choices. Considering the recent emphasis in health care on empowering patients, preventative care, and individual efficacy, the focus on individual behaviors is understandable. Discussions in health literature about obesity are an example of a health issue in which the ideology of individualism is often used.

Obesity is a physical condition that is most commonly argued to be the result of individual lifestyle and 
nutrition behaviors. Doctors usually prescribe a low fat, low calorie diet and increased exercise as the first form of prevention or treatment for obesity. In addition to the reduction in the potential risk for chronic disease, many medical practitioners argue that by reducing obesity through reduced fat and caloric intake, one may also reduce the risk of mortality as a result of chronic disease.

While it would be irresponsible for medical practitioners to ignore the role individual lifestyle and behaviors play in health outcomes, other potential risk factors can and should be explored. Broadly defined, these risk factors may include living in unhealthy environments created by racist social policies and behaviors related to surviving in an oppressive society.

Coveney (1998) describes the individualistic framing of current models of health promotion in the following excerpt :

In each, the subject or the collect subject (the community) is required to be self-reflexive and self-regulating in order to make 'proper' decisions. The judgement as to what is proper is dependent upon principled positions of the various streams of health 'promotionisms' (465).

Individualistic approaches assume that ways of living 
and behaving occur within a vacuum. From this approach, culture or environment may make it difficult for an individual to make 'proper' decisions about lifestyle or behaviors, but individuals are the source of the solution when health problems exist. At the same time, 'expert' medical practitioners have defined the 'proper' choices for the general public and serve as intervention specialists.

Some researchers have pointed out that Black women are rarely studied as a social entity in and of themselves (Allen 1981; Cummings and colleagues 1993; Fine and Gordon 1989; Townes 1998). Most existing studies on Black women's health and mortality focus on comparing Black women with other groups, Black men and white women in particular (Allen 1981; Arfken and Houston 1996; Bennet 1991; Gates and McDonald 1997; Kumanyika and colleagues 1989). Allen (1981) describes the problem:

All too often, analyses of Black females as a specific race-sex sub-group are deferred, the assumption being that by analyzing the realities of Blacks and women we also encompass the realities of Black women. We have seen above that such reasoning is correct only within certain limits. In important and significant ways the realities of $\mathrm{Black}$ women diverge from those of Black men and white women; for this reason they should be studied independently of these two groups (40). 
Studies comparing Black women and other groups have shown that differences in behaviors and health outcomes exist; however, the sources of these differences have been investigated through limiting paradigms. In particular, the possibility that health and mortality differences between $\mathrm{Black}$ women and other groups may be due to the combined effect of race and sex oppression remains largely unexplored.

Black women experience multiple forms of oppression while living in communities overwhelmed by social, political, and economic hardships. Neglect of race and sex oppression in discussions of Black women's health may be contributing to our lack of understanding of the differences in health and mortality between Black women and other groups. Studies that take race and sex oppression into account, on the other hand, have demonstrated the impact of racism and sexism on Black women's health outcomes. These studies include Thompson's (1994) study of eating problems, and Leclere, Rogers, and Peter's (1998) study of neighborhood social context and women's heart disease mortality, which will be discussed in Chapter II of this thesis. 


\section{Traditional Models of Disease}

The three main theoretical approaches used to explain differences in health outcomes are illustrated in Figure 1. These theoretical approaches are: genetic/biological, cultural/behavioral, and structural/socioeconomic (Krieger and Bassett 1993).

Genetic/biological model. Genetic/biological approaches (Figure 1) attribute health and mortality differences to genetic and biological traits associated with an individual's age, race, and/or sex (Cooper and David 1986; Crews and Bindon 1991). These approaches argue that an individual is biologically more susceptible to disease at birth because of the genes they inherited from their biological parents and family. One of the problems with these models is that they focus on individuals and divert attention away from social arrangements and policies that shape the health status of groups (Williams and Collins 1995).

Differences in male and female life expectancy are due, in part, to gender roles and gender inequality. Males have higher rates of accidents due to hazardous occupations, usage of illicit drugs and alcohol, gun 
injuries, and automobile accidents. Although the gap between the rates of heart disease among males and females is narrowing, scientists theorize that males have higher rates due to high rates of smoking and mismanagement of stress.

The problem with racial attributions is that, although people of the same "race" share a gene pool, there is more genetic variation within racial groups than across groups (Fee and Krieger 1994; Hummer 1996). All humans share about $95 \%$ of their genetic make up (Lewont in 1982). It is likely that social status and lifestyle account for more of the variance in health than genes. Hummer (1994) writes:

Missing from such interpretations is an understanding of the social significance of race in U.S. society and, especially, how health and mortality outcomes may be affected by many social and biological factors related to race that are both difficult to statistically control and not genetically determined (108).

Krieger and others have outlined some of the other problems with this approach (Krieger and Bassett 1993; Fee and Krieger 1994; Cooper 1986; Crews and Bindon 1991) . Krieger and Bassett (1993) summarize the basic argument against the identification of "race" as a genetic 
contributor to illness. They argue that it is not evident that: "race" genes are linked with genes that affect health; health is genetically determined; "race" is a valid biological category; or the health of a community is the consequence of the genetics of the individuals within the community.

Members of the same biological sex may share similar reproductive capacities; however differences in their life experiences (e.g. exposure to harmful substances, injury, type of work) influence health outcomes. Although Black and white women share the same biological sex, there are several differences in the incidence of chronic disease among them. Research by LeClere, Rogers, and Peters (1998) demonstrate that the different social context in which Black and white women live may partially explain some of the differences between Black and white women's heart disease mortality rates. Their study provides evidence that Black and white women of the same class experience social support in different ways and that this has an impact on health and mortality outcomes. Cultural and behavioral model. Cultural and behavioral attributions explain that health is the result 
of an individual's culture and lifestyle. This approach attributes chronic diseases to unhealthy eating habits, drug and alcohol abuse, lack of exercise, and failure to seek health care in a timely fashion. Krieger and Bassett (1993) write:

Promoting "health education" as a panacea, the government hopes to counsel minorities to eat better, exercise more, smoke and drink less, be less violent, seek health care earlier for symptoms, and in general be better health care consumers. This "lifestyle" version of the environmental model accordingly is fully compatible with the genetic model (i.e., genetic disadvantage can be exaggerated by lifestyle choices) and echoes its ideological messages that individual shortcomings are at the root of ill health (166).

The choices that individuals make "of their own free will" cause them to have negative health outcomes.

Alternatively, individuals can choose to behave and live differently, if they want to have good health. Zola (1983) writes that cultural/behavioral attribution theorists would argue that, although elements of our society are stressful, by living "right" we can overcome the materialistic, achievement oriented, and stressful society in which we live.

Structural/socioeconomic model. While maintaining focus on individual behavior, structural/ socioeconomic 
attributions do acknowledge the impact of socioeconomic inequality on health outcomes. Inequality affects health outcomes directly through the concentration of economically disadvantaged people into unhealthy living and working conditions and indirectly by constraining their health behaviors. The "poverty environment" in which Blacks live is theorized to have a direct effect on their health in that it is often associated with polluted inner cities and toxic chemicals (lead paint, waste dumps, and treatment plants). In addition to these unhealthy living environments, Blacks are more likely to work in jobs that expose them to harmful chemicals and hazardous working conditions (Bullard 1994; Mohai and Bryant 1992).

Some researchers argue that inequality constrains an individual's behavior indirectly in three ways: access, social roles, and household composition (Devine and olson 1992; Turrell 1998; Hawe 1998). Access is most commonly discussed in terms of geographical access to facilities, access to education and information about health, and access to financial resources. First, people of similar racial and economic standing tend to live in the same 
general geographical locations. These locations are not desirable to many medical clinics, hospitals, and specialists, and this makes it difficult for some to simply get health care.

The second way that access is constrained is through racial and economic inequality. Racial and economic inequality limits access to education and information about health care. People at all levels of education have a difficult time understanding health problems, medical treatments, and how to live a healthy lifestyle. It can be even more difficult for people who come from different cultural and economic backgrounds to understand health issues as well as to access accurate information about health.

The third way access is constrained is through financial resources such as low wage jobs, lack of employer-provided or subsidized health insurance, and limited paid time off from work. This constrains access to medical services. For example, many people who work in low paying jobs do not have any form of health insurance provided through their employment or can not afford it due to their low wages. Additionally, many people working 
in these low paying jobs do not have paid vacation or sick leave.

Social roles constrain health behaviors in that they physically and emotionally overwhelm a person, and they often conflict with each other. Women's health behaviors have been found to be constrained by their social roles (Devine and Olson 1992; Simon 1997; Thoits 1999). For example, Devine and Olson's (1992) study of women's social roles and nutritional care provides evidence that women have many nutrition-related roles during their lifetime and that these roles can have both positive and negative effects on their nutritional behaviors. Social roles can become more complex and varied depending on the composition of the household in which women live.

Finally, although rarely discussed, household structure can constrain health behaviors. Turrell's 1998 study of determinates of healthy food choice found that respondents who lived in households with fewer people were more likely to purchase dietary guideline food than those with more complex households.

In short, in households where there are multiple demands and preferences being voiced, there is a reduced propensity to purchase dietary guideline food (Turrell 1998;355). 
Turrell found that single people living alone were more likely to choose "healthy" food than people who lived in households with several people. This finding is similar to that of Devine and Olson (1992) in that the women experienced conflict in their roles as family food manager and peacekeeper. In addition, Devine and Olson found that the "independent" group of women felt less role conflict and were less constrained in their personal nutritional behaviors.

Typically, the solutions proposed for these problems are targeted at changing individual behavior. For example, Domel and colleagues (1992) argue for "culturally sensitive, simple, and straightforward (without belittling)" nutrition education programs for Black women to help them control their weight. Ultimately, cultural/behavioral attributions argue that the way to close the gap between Black and white health and mortality outcomes is to educate minorities to eat better, seek health care sooner, and exercise more. This tendency toward policies and programs to change behaviors of individuals are short term and ineffective solutions to what is in fact a wide-ranging social and economic problem 
(Hummer 1996).

Kreiger and Bassett (1993) argue that although they differ in important ways, cultural/behavioral and structural/socioeconomic attributions have similarities. Structural approaches acknowledge the impact of institutional racism on the health of minorities both directly and indirectly; however the solutions presented are most frequently focused on the individual. Both cultural/ behavioral and structural/socioeconomic perspectives focus on changing the health behavior of individuals.

The solutions proposed by cultural and structural attributions assume that intervention by experts is the key to improved health. Where cultural/behavioral theorists are more punitive and structural/socioeconomic theorists more supportive, both approaches assume uncritically the perspectives of race, class, and gender-biased authorities. They fail to acknowledge the power of the position that health care practitioners hold, the direct effect of race, class, and gender oppression on health, and the ways that oppression shapes the lives and behaviors of individuals (Balshem 1993; Kreiger and 
Bassett 1993; Scott 1991; Leclere, Rogers, and Peters 1998). They do not consider that some individuals make choices as a way of responding to, surviving, and resisting the oppression that they experience in their lives (Thompson 1994).

other researchers are similarly critical of traditional models of health and mortality because they neglect the macro level, social, and economic determinants of health (Hawe 1998; Krieger and Sidney 1996; Krieger and Bassett 1993; Anderson 1996). Hummer (1996) argues that structural/ socioeconomic attributions often fail to consider the sources of socioeconomic differences between Blacks and whites (race) and males and females (sex). He further argues that individual and institutional levels of racism are often ignored or reduced to socioeconomic differences, and that the differences in education, income, and or occupation are used to compare socioeconomic status, while related inequalities are left unmeasured. Such things include household wealth, family and community dynamics, and differences in treatment by health care providers based on race, sex, or class status. 
Additionally, some scholars point out that the focus on individual change ignores the ways in which the context in which we live affects our health (Krieger and Sidney 1996; Fee and Krieger1994; LeClere and colleagues 1998, Anderson 1996, Devine and Olson 1992; Hawe 1998; Crotty 1995; Thompson 1994; Shy 1997; Williams and Collins 1995). For example, Joan Anderson (1996) argues that social and economic inequalities impact health and prevent individuals from being empowered to take responsibility for their own health. Anderson writes that individuals will be empowered within the health care system when medical practitioners begin to recognize and discuss the historical factors that have shaped social institutions. She maintains that systemic discrimination makes empowerment within the health care system meaningless to the disadvantaged and marginalized. "Achieving health is not just a matter of enabling people to take more responsibility for their health; it is also about naming injustice and taking action to address social and economic inequality" (Anderson 1996:704).

Alternative model. Hummer (1996) captures many of these critiques in his model for understanding 
Black/white differences in health and mortality (Figure 2). Hummer's model differs from the previously discussed models in two ways. First, he considers the importance of race in U.S. society for creating laws and policies that perpetuate racial stratification. Racial inequality operates through institutional forms of racism, racial socioeconomic stratification, and individual level experiences of racism to shape access to health care, physical environment, social roles and support, levels of stress, and coping behaviors. These factors, in turn, have a direct impact on health. Second, Hummer considers the effects of discrimination and stratification on the levels of stress and coping behaviors. Stress and coping behaviors in turn influence health and mortality.

I add to his model gender discrimination. I argue that gender stratification operates to affect health in a similar fashion as racism. Black women experience race and gender stratification simultaneously, and any analysis of their health status would be incomplete without including both dimensions.

Explanations that include race, class and sex move the examination of health beyond the individual and group 
level, focusing instead on the social, political, and economic context in which people live and health behaviors occur. Alternative attribution theorists argue that some individuals make choices as a way of responding to, surviving, and resisting the oppression that they experience in their lives (Thompson 1994; Scott 1991; LeClere and colleagues 1998; Balsham 1993). For example, in her research on women's eating problems, Thompson (1994) found sexual abuse, poverty, limited power, education and employment barriers, and women's socialization to care for others at their own expense to be some of the social forces at the core of women's eating problems. Thompson argues that eating problems are often "logical, creative responses to trauma" (1994:2).

In this section I have provided some basis for conducting research using medical journals and their explanations for why there are different health and mortality outcomes among Black women and other groups. The models described in this section provide a framework for reviewing the literature relevant to this study. In addition, these models serve as a guide for coding the various explanations of health differences that are 
contained within the journal articles (See Appendix A). Understanding these explanations is important because medical practitioners often rely on these articles and these articles help shape their thoughts about and treatment of patients. 


\section{CHAPTER II}

\section{LITERATURE REVIEW}

To my knowledge there has not been any research conducted on the content of articles in medical journals as it relates to explanations for health and mortality differences among Black and white women specifically. There is, however, some research that provides support for Hummer's (1996) alternative model. These studies have made racism and sexism central to understanding the differences in health outcomes. Although there have not been many studies conducted specifically on the effect of oppression on health, nor much discussion about the context in which behaviors occur, the studies that have informed my approach are:

Krieger and Sidney's (1996) study of blood pressure and racial discrimination;

Scott's (1991) research on Black women's survival;

Leclere, Rogers, and Peters' (1998) study of neighborhood and mortality rates.

Thompson's (1994) research on women of color and lesbians and eating problems; and

Balshem's (1993) research on working class resistance to medical advice. 
All of these studies, discussed in the following section, provide support for an alternative model of health and mortality. In most cases, the researchers discussed race, class, or gender oppression, the situations created by oppression, and ways people responded to these conditions. Their explanations suggest that race and gender operate through institutional and individual forms of oppression and socioeconomic stratification to influence health care, physical environment, health and coping behaviors, stress, and social roles and support, all of which, in turn, affect health and mortality.

\section{Race and Sex Oppression}

$$
\text { Krieger and Sidney's (1996) study of racial. }
$$

discrimination and blood pressure among young Black adults illustrates Hummer's model. Krieger and Sidney looked at perceptions of racial discrimination and the impact of coping behaviors and stress on blood pressure (health outcome). Their study found that experiences of racial discrimination and responses to discrimination were associated with blood pressure levels. Black/white differences in blood pressure was highest among working class $\mathrm{Black}$ women and men who reported experiencing no 
racial discrimination, Black women who reported experiencing racial discrimination but accepted it as a fact of life and kept it to themselves, and Black men who accepted unfair treatment but talked to others about it.

Kreiger and Sidney (1996) write that those who deny that they have experienced racial discrimination or accept it may have internalized their experiences to the extent that increased blood pressure is the result (1375). Professional $\mathrm{Black}$ women and men had lower blood pressure and were more likely to report experiencing and responding to racial discrimination. They may feel more comfortable reporting and challenging discrimination because of the security provided to them by greater social and economic resources. Based on their research, Krieger and Sidney predict that the differences between Black and white blood pressure might be reduced by 28 to $56 \%$, if working-class Black men and women had experienced racial discrimination in only one or two of the situations described in their study.

This study has important implications for understanding and potentially decreasing the differences 
in the health status of Blacks and whites in the United States. It provides evidence that racial discrimination, beyond the obvious economic consequences, affects the physical health of Blacks when it is not challenged.

Despite the preliminary nature of our findings, one clear implication is that analyses of "Black-White" differences in blood pressure should take into account social meanings of race/ethnicity, as embodied in experiences of racial discrimination. They should also consider how social class and gender affect exposure to and embodiment of racial discrimination (Krieger and Sidney 1996:1376).

This research provides some evidence that there are other unknown or untested explanations for different health and mortality outcomes among Black and white women in the United States. Such attributions include the direct effect of discrimination on physical health and the limited coping mechanisms available to oppressed groups.

Other researchers provide examples of the ways that racism and sexism create oppressive conditions and multiple roles for Black women. In The Habit of Surviving, Kesho Scott (1991) describes some of the situations in which Black women must survive and resist oppression during their lives. Scott defines the habits of surviving as: "the external adjustments and internal adaptations 
that people make to economic exploitation and to racial and gender-related oppression " (1991:7). Habits have served to help Black women cope emotionally and physically. Acceptance and internalization of oppression are part of the habit of surviving. Acceptance and internalization allow social, political, and economical survival while at the same time contributing to physical stress. Krieger and Sidney's (1996) research discussed previously is an example of how the internalization of racism has contributed to higher blood pressure for Blacks.

Scott identified four areas in which Black women experience race, class, and gender oppression and have developed the habit of surviving: society, Black community, family, and identity. Black women are socialized to tone down their reactions to racism and sexism to give the impression that they are acceptable. They are responsible for making people around them feel comfortable, to not threaten their bosses or white women in the feminist movement, and to not alienate Black men.

Scott writes:

The paradox of acting ladylike and being aggressive and businesslike is compounded for Black women by the stereotype of the domineering, loudmouth, manipulating 
Sapphire - to which they might be insultingly compared (154).

They are in the difficult position of meeting society's expectations by accommodating the needs of others and keeping their experiences of oppression to themselves, yet they are stereotyped as being difficult. To compound the problem even further, their community has assigned to them the role of protecting and nurturing the family. Scott writes:

Their roles as the makers and bearers of culture are designed to ensure the survival of the race and community. Their roles are also designed to operate within the traditions of Black male privilege, heterosexism, religion, and political activism (154).

In the family, their roles are parent (sometimes both mother and father), wife, and family networker. Scott identifies marriage and motherhood as a habit of survival for Black women because they have been taught that their survival as mothers is dependent upon marriage and that if they are married they should have children.

Motherhood and marriage can be viewed as habits of survival for Black women because Black women's patterns of survival have become inseparable from their roles as mothers (Scott 1991: 158).

As Scott wrote, when formal marriage between slaves was 
forbidden, marriage was used as a way to rebel against society. In more recent times, Black women have been socialized into believing that marriage and motherhood is the only way for them to acquire higher status in society. Although all of the women Scott interviewed were married at one time, they all expressed their desire to be free of their marital and family ties at some point in their lives. This reflects one of the ways that Black women experience dueling expectations and desires in their lives.

As mothers, Black women are responsible for protecting their children from racism and oppression, by teaching them about it and how to adapt to it, and urging them to strive for higher status. As maintainers of the culture, it is also the responsibility of Black women to teach their children about their cultural history and values. As members of an extended family, Black women are expected to maintain the pattern of support in their social network and extended family. This expectation is created and supported by their community's religion, politics, and economic structure. The women interviewed described the ways in which they support members of their 
extended family and how they were socialized into this support role by their family and community. For example as Scott (1991) writes:

Although these extended family relationships can be helpful, maintaining them puts a social, as well as psychological, burden on Black women. It is they who have the obligation to help poorer members of the family, to care for aging parents, and to take in needy children (162).

Black women have developed their self identity by accepting their given roles and status within society and believing that society values them. However, in realizing the contradiction between what they were taught and their experiences of oppression, they experience internal conflicts. They begin to question their identity and their value to society.

The crises in Black women's identities surface as they break the silence of survival to question their suffering and triumphs on the societal, community, family, and personal levels (Scott 1991:165).

Failed marriages, economic struggles, and inability to feel comfortable in their roles cause them to feel rejected and devalued by society. They begin to realize on a personal level that their self-created identity is missing. However, as one of Scott's respondents so aptly stated, even though they are consumed by the identities 
created for them, they still think about what they want for themselves and find ways to be happy.

Scott's interviews illustrate the complexity of the positions that Black women hold and particularly the overwhelming responsibility Black women have for providing and caring for others. They must find ways to cope with this responsibility, to survive it, or to resist it. Any choice they make will have a physical consequence for them.

In addition to the multiple forms of oppression and complex social roles confronting Black women, social support may also contribute to different health outcomes. Leclere, Rogers, and Peters' (1998) research on the effects of being a female head of household on coronary heart disease mortality among Black and white women provides an example of the effects of social support on health outcomes. They found that although Black and white women experienced similar rates of heart disease morbidity, Black women experienced higher rates of heart disease mortality. Using data from the Census, National Health Interview Surveys, and the National Death Index they found that women who live in neighborhoods with high 
concentrations of female-headed households are more likely to die of heart disease. In neighborhoods with high rates of poverty, $75 \%$ of the Black families were headed by females, compared to $35 \%$ of white families. They argue that there is a significant relationship between the higher rates of Black female heart disease mortality and the high rates of female-headed families in poor Black neighborhoods. Two possible explanations are identified: 1) Blacks are not likely to have extended social support networks outside of their poor neighborhood, causing stressful social obligations; and 2) although neighbors represent a source of contact and support, in neighborhoods with such high rates of poverty and female headed families, the neighbors also represent burdens. Leclere, Rogers, and Peters (1998) conclude:

This 'contextual' effect accounts for racial differences in heart disease mortality for women over 65 and supports the notion that the conditions of Black women's lives, both individually and collectively in the communities in which they live, hasten their deaths despite only slightly elevated rates of cardiovascular disease (103).

LeClere, Rogers, and Peters' research provides evidence that gender and race contribute to the difference in Black and white women's heart disease mortality. Their research 
is further supported by the previous work of Kessler and Neighbors (1986) examining the relationship between race, social class, and psychological distress. This research moved beyond the individual level of analysis to explore the neighborhood effect. However, other factors that may play a role in the disproportionate number of deaths were not explored. They have failed to recognize how racism and sexism create institutional and individual oppression as well as socioeconomic stratification.

Responses to Oppression: Coping, Resisting, and Rebelling

The previous discussion illustrates that Black women are likely to experience multiple forms of oppression with limited social support. As a result, they have developed ways of surviving and resisting oppression. Such strategies may include substance abuse, overeating, alternative medicine, and exercise. Thompson (1994) identified eating problems as both a way of surviving and of resisting race, class, and sex oppression. For some of the women she interviewed, the ways they ate were the healthiest and most reasonable methods the had to cope with the hardship in their lives. Eating allowed them to fulfill their day-to-day duties, while 
experiencing some form of escape or release from the pain in their lives.

Thompson (1994) conducted life history interviews with lesbian and heterosexual Latina, African-American, and white women about the effects of race, class, and gender oppression, acculturation, and sexual abuse on their eating habits. She identified three theoretical models used to explain eating problems: the biomedical model looks at the physiological causes and dangers of eating problems; the psychological model views eating problems as a "multidimensional disorder" that is influenced by biological, psychological, and cultural factors; and the feminist model views eating problems as one of the ways that women cope with oppression.

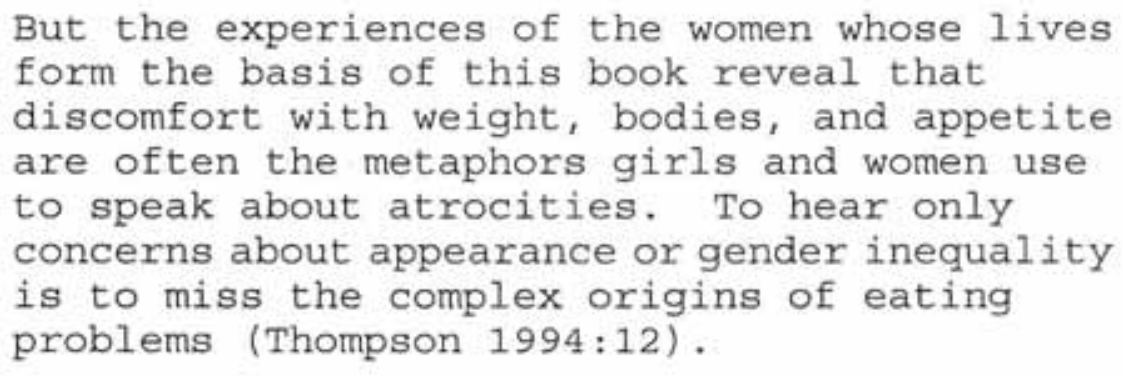
form the basis of this book reveal that discomfort with weight, bodies, and appetite are often the metaphors girls and women use to speak about atrocities. To hear only concerns about appearance or gender inequality is to miss the complex origins of eating problems (Thompson 1994:12).

Thompson identifies sexual abuse, poverty, limited power, education and employment barriers, and women's socialization to care for others at their own expense as some of the difficulties at the core of women's eating 
problems. Thompson argues that the eating problems are "logical, creative responses to trauma" (1994:2).

As applied, the biomedical and psychological models fail to recognize women of color and working class women as having eating problems. Thompson writes:

Compulsive eating, bulimia, and anorexia have taken on complicated symbolic significance in late twentieth-century culture in the United States. Those suffering from eating problems invariably are thought to be young, middleto upper-class, heterosexual white women desperately trying to mold their figures to standards created by advertisers and clothing designers. Such conceptions are misguided, short-sighted, and harmful. They are built on skewed assumptions about race, class, and sexuality that belittle the putative victims - white, middle-class, heterosexual women while they ignore women of color, working-class women, and lesbians (1994:1).

Thompson has suggested that research on wornen's eating problems is problematic for two reasons. First, research has attributed eating problems to women's preoccupation with appearance and second, it has focused exclusively on young, White, middle-class, heterosexual women. Those researchers who acknowledge that women of color and working class women are capable of creating symbolic relations with food beyond biological need challenge the commonly held belief that these women are not capable 
of developing problems that are both psychological and physical (Thompson $1994: 15$ ).

Thompson suggests that the women's families often pressured them to lose weight as young girls to protect them from the one form of discrimination they considered within their control, fat discrimination (1994:44). While parents may not be able to control race, class, and gender discrimination, they can try to influence the size of their daughter's body. Women's bodies are a place where battles take place and where pain is experienced. The women interviewed have used food to escape, medicate, and soothe the pain of sexual abuse, racism, sexism, and poverty.

Thompson looked beyond the individual to the social forces that cause objectification and pain in the lives of the women she interviewed. These women had to find ways of resisting the negative messages and coping with the pain. They used food as a way of resisting society's control over their bodies, escaping abuse and pain, and coping with poverty and loneliness. Their confusion, created by the messages they received about what was an acceptable body size, was reflected in their weight 
fluctuations. Thompson's research provides an excellent example of how women of color and lesbians have used food to cope with and resist race, class, and gender oppression. Resistance was identified by Balshem (1993) as the source of many of the behaviors of the working class people in her study. The belief that individuals have little control over their life circumstance is central to the working class experience, this being in contrast to the experiences of the health educators and scientists giving them health advice (Balshem 1993:85). The experiences of health educators and scientists lead them to believe in the efficacy of individual action. In addition, for health educators, the legitimization of their expertise and the importance of their profession require that health education be central to disease prevention. One of the things working class people resisted was scientific authority and knowledge. Balshem found that twice as many people she interviewed believed that cancer resulted from environmental factors (such as toxins, pollution, food additives) than lifestyle (e.g. diet, exercise, substance use/abuse).

Bridgett Davis (1990) presents an example of an 
individual feeling little control over life circumstance.

In her essay "Speaking of Grief: Today I Feel Real Low, I Hope You Understand." Davis talks about the enormous grief and sorrow she has experienced as a Black woman. Having lost five family members in an eight-year period of time, she felt she had no control of her life circumstances:

I think I now know, too, why I was grieving. Not just because the deaths had each been, to my mind, senseless and avoidable. Not just because I would miss my loved ones intensely, knowing I could never share my discoveries, my triumphs, my own life with them again. But because I felt helpless. And because I believed, deep down, that living as a struggling Black family in a hardened urban city had more than a little to do with my family's fate. At times, I blame the individuals who pulled the trigger in the case of my sister, my brother and my nephew. At other times, I blame the system - a system that can allow Black people to struggle so hard for so little, to work against arbitrary obstacles to acquire the basics that all human beings want, to accept multiple hardship and loss as a given way of life. To bleed inside and think all we deserve is a band-aid and a lecture about working harder (Davis 1990:223).

Davis talks about Black women being familiar with and expecting tragedy and death in their lives. At the same time that they are coping with loss, they must go on and live their lives. Blacks in the U. S. are coping with 
hardships such as high infant mortality, low life expectancy, high rates of homicide, high rates of $\mathrm{Black}$ male incarceration, high rates of drug and alcohol abuse, and dehumanizing ghettos.

Balshem (1993) points out that the people in her study did not want to be the targets of science and viewed as sick. They feel judged by science. It is the scientists who have authority and hold the "truth."

Like the residents of Tannerstown, I saw the literal message as being transformed by the social relations through which it was transmitted. No amount of "cultural sensitivity" in health-education practice will speak to this root problem. The world of the message makers needs fundamental change (Balshem 1993:145).

Balshem agrees that the focus of our inquiry should be redirected to the "authorities." Members of Tannerstown expressed frustrations about the contradictory messages they receive. They argue that some of their ancestors did not get cancer, despite their "unhealthy" behaviors and that some who exhibited "healthy" behaviors sometimes got cancer and died. The contradictory messages and the lives they have witnessed cause them to distrust "authority" figures. The "authorities" that come into their community and create education forums expect the 
residents to accept their professional knowledge as truth, accept their authority, and accept blame for disease. Balshem argues that we must look at the context in which educational forums take place. These forums often belong to scientists and medical authorities. The audience (target) is often disempowered and alienated in the process. Their way of rebelling is to fake compliance with the authorities' advice. Rebellion is an important part of their identity. "The maintenance of a rebellious consciousness is part of the construction of valued self, valued community, valued life, in a subordinate class environment" (Balshem 1993:87). It is the way that they can have some control of their lives, survive hardships, and honor their history as people with relatively little power.

The literature in this review illustrates some of the "alternative explanations" described in the Alternative Model of Health and Mortality (Figure 2). This research has placed race and gender oppression at the forefront in understanding health and mortality. Krieger and Sidney's research has shown how racial discrimination has a direct impact on blood pressure, 
Scott's research illustrates the oppressive situations and multiple, conflicting roles within which Black women must cope, and LeClere and colleagues' study of social support demonstrates the contradictory impact of social networks within contexts of race and gender oppression. Thompson explored how contradictions in the coping strategies of women affect their health outcomes, while Balshem similarly explored how resistance to class oppression shapes the relationship between working-class people and health providers as experts. These studies provide alternatives to the more traditional approaches to understanding health outcomes.

\section{Research Questions}

The goal of this study was to examine and analyze the attributions made about Black women's health in three major medical journals (JAMA, NEJM, and AJPH). MY research questions are as follows:

1. With what frequency do researchers employ the four types of attributions to explain health and mortality differences among Black and white women?

2. Is there any relationship between the topic of the article (subject) and attributions used to explain health outcomes?

3. Are there any changes in the attributions used over the ten year time period (1989-1998)? 
4. Are there any differences in the attributions used by gender and race of the study population?

5. Are there any differences in the attributions used by the journals? 


\section{CHAPTER III}

\section{METHODS}

\section{Sample Selection}

The data for this project came from articles

published during a ten year period (1989-1998) in three major health-related journals: the American Journal of Public Health (AJPH), the Journal of the American Medical Association (JAMA), and the New England Journal of Medicine (NEJM). These journals were selected because they have a large professional readership that includes researchers, educators, and medical practitioners. All of the journals are refereed serials that have been in publication for over 80 years and have a distribution of $36,500-372,000$. The articles were selected using PubMed, a database of over 9 million citations in MEDLINE that is supplemented by pre-medline citations and citations that were supplied electronically by publishers. MEDLINE is a database for medical and health care literature.

The PubMed search database contained 92,317 article citations for the NEJM, the AJPH, and JAMA. Of all of the articles contained in the database for these three 
journals, $1.29 \frac{2}{\%}$ of the subheadings contained the words Black/ African American and $.33 \%$ contained the words Black/African American and women (Table 2). Since this study was focused on a ten year time period, from 1989 to 1998 , the articles that remained after the initial review (135) accounted for $.22 \%$ of the total articles within the PubMed search database for these journals. The AJPH contained the fewest articles overall (.09\%), but had the greatest number of articles containing the words Black/African American and women in the subheading $(.96 \%)$ when compared to the NEJM and the JAMA (with $.06 \%$ each).

Table 2 reports the number of articles reviewed in each journal. PubMed search database identified a total of 1,194 articles with subheadings that contained the word Black/African American, 303 with the words Black/African American and women, and 203 with the words Black/African American and women between the years 1989 and 1998. Nine percent of the total articles $(92,317)$ were American Journal of Public Health (AJPH) articles, $44 \%$ were New England Journal of Medicine (NEJM), and 47 
$\%$ were Journal of the American Medical Association (JAMA) articles.

The distribution of the articles changed as the criteria for selection were narrowed first to Blacks/African Americans, next to Blacks/African Americans and women, and finally to Blacks/African Americans and women between 1989 and 1998. Once the selection was narrowed to Blacks/African Americans and women between 1989-1998, the AJPH had more articles than NEJM and JAMA selected for review (Table 4). Over half of the 135 articles that were reviewed for this study came from the AJPH $(60 \%)$. The NEJM and the JAMA each contained $20 \%$ of the articles reviewed. The number of articles reviewed ranged from a low of 6 in 1989 to a high of 20 in 1993 . The AJPH always had the most articles reviewed with the exception of 1989 when the NEJM had one more than the AJPH.

The process for selecting articles was threefold. First, I used the PubMed search data base to identify articles published in the three journals. Second, I narrowed the citations down using Black and women as specific subheading search terms. This search generated 
58 article citations for JAMA, 31 for the New England Journal of Medicine, and 116 for the American Journal of Public Health (total of 205). Finally, I conducted a review of the articles to select those meeting criteria for analysis. This review removed from the sample citations that were letters, editorials, reviews, and statistical reports and left 135 articles for analysis.

In the third review, I analyzed the content of the remaining 135 articles

\section{Coding Categories}

A coding sheet (Appendix B) was developed to collect data on each article. Every article reviewed was coded in such a way that the data could be traced back to individual articles. In addition, the coding sheet included general descriptive information such as the title, author, date of publication, page length of the article, topic (see Appendix D for description of topic grouping), and a summary of each article's main findings.

The data analyzed included explanatory content of the article, the referent population (sex and race/ethnicity), and the total number of genetic/biological, cultural/ behavioral, structural/socioeconomic, and alternative 
attributions that occurred in each article.

Representative statements of authors' explanations for findings were also collected. The explanations were coded using the criteria outlined in the models (Figures 1 and 2 and Appendix A) informed by the work of Krieger and Bassett (1993) and Hummer (1996).

Using the coding sheet (Appendix B), I looked for sentences and phrases within the articles that made an attribution about the determinants of Black women's health or mortality. These explanations were each placed into one of four categories: genetic/ biological, cultural/ behavioral, structural/ socioeconomic, and alternative (see Appendix A). Most articles included several types of explanations. For example, Tielsch et al $(1991)^{9}$ in an article on glaucoma, state:

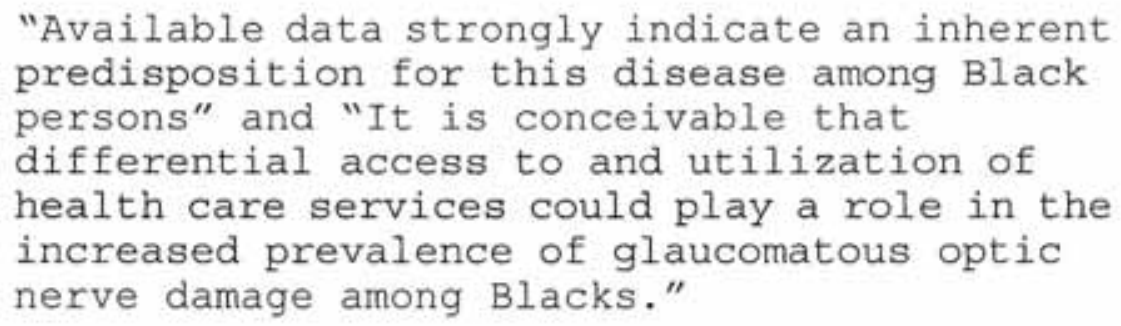

Each of these quotes represents a different type of attribution. In the first quote, the authors explain that the differences may be attributed to a genetic 
predisposition to glaucoma (genetic/biological); in the second quote the authors consider access (structural) and utilization (cultural/behavioral) as possible explanations for the differences in the prevalence of glaucoma. In this study, each explanation was coded separately. Among the 135 articles reviewed, there were a total of 618 explanations given and coded. The citations for quotes used as examples in this thesis are listed in Notes (Appendix C).

\section{Variable Grouping}

Articles were grouped into nine different topic areas (Figure 4): Sexually Transmitted Diseases/Human Immunodeficiency Virus (STD/HIV); Reproductive; Coronary Heart Disease/Cardiovascular Disease (CHD/CVD); Smoking/ Behavior/ Obesity (Behaviors); Mortality; Services/ Treatment (Services); Cancers; Accidents; and Degenerative Diseases. Topic areas are general categories identified while reviewing the article heading and subheading. For example, if an article heading or subheading indicated that the topic was premature birth, low birth weight or health during pregnancy the article topic was coded as reproduction (see Appendix D for more 
examples of topic grouping). Figure 4 displays the distribution of the 135 articles within these nine topic areas.

The articles were also grouped into six groups by populations under study: Black females only (B F), Black and white females only (B/W F), Black and other females $(B / O F), B l a c k$ males and females $(B M / F), B l a c k$ and white males and females $(\mathrm{B} / \mathrm{W} \mathrm{M} / \mathrm{F})$, and $\mathrm{Black}$ and other males and females $(\mathrm{B} / \mathrm{O} \mathrm{M} / \mathrm{F})$. The other category is any combination other than Black and white alone (e.g. Black and Hispanic, Black, white, Hispanic, and Asian, Black, Native American) . 


\section{CHAPTER IV}

\section{RESULTS}

\section{Frequency and Patterns of Attributions}

Genetic/Biological Attributions. In the articles

I reviewed, eight percent of the explanations for

difference between Black and white people's health

outcomes were categorized as genetic/biological

differences. For example, in an article on smoking and low birth weight, one explanation implied that Black women react in a biologically different way to smoking than white women, "Thus, these data suggest that the per-cigarette effect on birth weight may be greater in Blacks than in Whites" ". The next explanation, in this article, argues that "...these data suggest that cigarette smoking among Blacks may have a greater effect on birth weight than it does among Whites" ${ }^{4}$.

Later, in the same article, the authors site a specific scientific explanation for why cigarette smoking may have a greater effect for Blacks, "First, it has been previously suggested that the higher levels may be due to differences in nicotine metabolism" "4. These explanations are coded as genetic/biological rather than 
cultural/behavioral because smoking is discussed as having different outcomes because of something inherent in being Black or white. This inherent difference is attributed to metabolism, which is a chemical and physical processes that is beyond an individual's control.

The highest number of genetic attributions occurred in 1994. Genetic attributions exceeded alternative explanations in most of the years reviewed with the exception of the years 1993 and 1996. JAMA had the highest percentage of genetic explanations, with $12 \%$ and the NEJM had the lowest percentage of $7 \%$ (Table 6$)$. Within the race/sex groups, genetic attributions occurred most frequently among research articles that compared Black and white females and Black males and females, but less frequently when comparisons were made between Blacks and other ethnic groups (Table 7). The largest proportions of genetic attributions were in the topics of degenerative diseases $(21.57 \%)$ and cancer $(17.65 \%)$. The smallest proportions of genetic attributions were in the topics of mortality (3.92\%) and accidents (3.92\%) (Table 8).

Cultural/behavioral attributions. In the following statement, several cultural and behavioral attributions 
are made to explain the differences between foreign born Black women and U. S. born Black women,

Foreign-born women were more likely to be older, married, better educated, to have better pre-pregnancy weight-for-height, and to have had nine or more visits for prenatal care than those born in the US. The two groups of women were similar on parity, trimester of first prenatal visit, and pregnancy weight gain of less than 16 lbs. They were also less likely to smoke cigarettes, drink alcohol, or use marijuana, cocaine, or opiates during pregnancy; in addition, they used fewer cigarettes and consumed less alcohol. ${ }^{1}$

This statement, which was taken from an article in the AJPH, refers to the fact that women who delay pregnancy until they are older, married, better educated, and physically healthy are likely to have better birth outcomes. In addition, the statement adds, these foreign born women are more likely to not participate in drug and alcohol use. However, there is no discussion of the socioeconomic and political factors that contribute to these conditions and behaviors.

In the following explanations, the authors imply

that their subjects may not be honest in their reporting:

Second, a possible explanation for this racial difference could be differential self-report. ${ }^{4}$

It may be that women who report other types of injuries (i.e., blunt trauma) may also, in 
fact, have suffered injuries resulting from violence. ${ }^{5}$

While it is possible that subjects of a study may not be completely honest in their reporting there is no reason to assume that this reporting behavior differs by race. These statements imply that Black women may not be as honest as white women respondents. There are no data to support this finding, nor is there any discussion about how the authors developed these attributions. If it is true that some women do not report their injuries as resulting from domestic violence, then the researchers should at least consider factors that may contribute to dishonesty on the part of Black women regarding these issues.

Some explanations make specific reference to differences in health behaviors, compliance with medical advice, and utilization of health services. In the following examples, cultural beliefs are cited as an explanation for the differences:

Our previous analysis of the open-ended portion of the interviews with African American women with late-stage disease allows some understanding of the reasoning process involved and demonstrates that cultural conceptions of breast lumps and cancer directly influence women's recognition and evaluation 
of breast symptoms. These women interpreted their symptoms with reference to a traditional or "folk" model of the blood. In terms of this model, breast lumps are not necessarily bad. They are a normal part of a woman's system as evidenced by the fact that if left alone, they tend to come and go. ${ }^{12}$

Obviously cancers discovered by screening at an early stage do not become advanced, and therefore, part of the explanation may be that the cultural beliefs were associated with differential use of screening mammography. ${ }^{12}$

In some other explanations compliance was indicated as one of the reasons for differences in health and mortality:

Since Hispanics in our study had income and education levels similar to those of black participants, the availability of heath services does not appear to contribute to lower rates of self-reporting, although it remains possible that blacks are less likely to use health facilities despite similar availability. ${ }^{10}$

In addition, whites were more likely than blacks to have CABG surgery after it was recommended by their physician, and they were also more likely than blacks to have CABG surgery when medical therapy was recommended, suggesting that patients' willingness or ability to proceed with CABG surgery may vary by race. ${ }^{11}$

In the following example, the authors make reference to socioeconomic status (SES) specifically, but refer back to "health practices" as the solution: 
At least part of the disadvantage associated with low socioeconomic status relates to poorer lifelong health practices in this group, and efforts must continue to improve these practices. ${ }^{14}$

This explanation is again focused on individual behaviors rather than the overarching disadvantage that creates a context in which individual are exposed to conditions that threaten their health. For example, the quality of housing and food available to people who live in poor communities.

The highest number of cultural/behavioral attributions occurred in 1990 and the lowest number occurred in 1989 (Table 5). However, in relation to the other attributions, cultural attributions accounted for $59 \%$ in 1990 , the only year in which cultural attributions accounted for a higher percentage of the explanations than structural attributions. The NEJM had the highest percentage of cultural explanations with $44 \%$ and the AJPH had the lowest percentage (37\%). Within the race/sex groups (Table 7), cultural attributions occurred more frequently among research articles that compared Black and other males and females. The others group includes 
race/ethnic groups such as Asian, Hispanic, and Native American.

The topics in which cultural attributions occurred most often were STD/HIV (Table 8). Cultural attributions accounted for $59 \%$ of the explanations for this topic. Cultural attributions also accounted for a high percentage of the explanations when the topics were CHD/CVD and behaviors. This attribution was used less often when the topics were services $(4 \%)$.

Structural/socioeconomic attributions. There were two main areas in which attributions within the articles typically fell, bias/discrimination and constrained access. In the following quotes some form of bias or discrimination on the part of institutions or individuals is implied:

Aggressive marketing by tobacco companies in these neighborhoods may be a contributing factor. ${ }^{2}$

Health care providers may be giving advice based on their stereotypes of who is involved in what type of behaviors and not on a principle of equity. ${ }^{3}$

Physicians were less likely to recommend CABG surgery to blacks than whites, despite equivalent numbers of diseased arteries and more severe angina among blacks, suggesting 
physicians were more aggressive in their

therapeutic approach for white patients. ${ }^{11}$

In the first quote, the authors consider the importance of targeting by companies that promote the sale of harmful substances. This kind of explanation occurred in only three or four of the articles I reviewed. In the second and third quotes the authors point to discriminatory actions on the part of individual doctors treating patients.

Other explanations looked at the importance of place in contributing to discrimination, harmful environment, and limiting access:

Second, the site of prenatal care was important. Advice on illegal drug use was more common for patients of publicly funded sites and hospital clinics than for private-office patients. ${ }^{3}$

It is likely that a factor such as living in public housing is a marker for other environmental exposures that were not measured in this study. 7

Site of care was often referred to as one of the contributors to health differences. This was most often discussed in terms of location of services in public versus private hospitals and clinics. There was also mention of differences in types of services available 
to a population. Discussion of pollution and toxins in the community were rare. The last two examples place emphasis on access to jobs and education:

The current study corroborates the lower job control that Black women have compared with White women, but it is also found that Black women experience lower job demand. ${ }^{6}$

Increasing the likelihood that a person will attain a high level of education not only may be advantageous for that person's young and middle years as a wage earner but also may be a valuable investment in increasing his or her years of active, non disabled life after retirement. ${ }^{14}$

In these quotes, the authors refer to work as a contributor to health problems. In the first quote the authors raise differences in employment, specifically control within work environment and job demands as potential explanations for differences between Black and white women's health and mortality. In the second quote the authors discuss the relationship between educational achievement, wages, and active life expectancy. Structural/socioeconomic attributions occurred most often in 1995 and least in 1994 (Table 5). However, in relation to the other attributions, structural attributions accounted for the highest percentage of the explanations in most years. Structural attributions 
occurred less often than cultural attributions in only one of the years studied, 1990. The AJPH had the highest percentage of structural explanations with $50 \%$ and JAMA. had the lowest percentage $(43 \%)$, however the percentage of explanations did not vary much by journal (Figure 7). Among the race/sex groups, structural attributions did not vary much (Table 7). Structural attributions did occur more when among the Black/other female study populations than among any of the other populations (54\%) . Structural attributions accounted for $80 \%$ of the explanations when the topics were services (Table 8). However, structural attributions accounted for the highest percentage of the explanations for five out of nine topic groups. Cultural attributions were highest when the topics were STD/HIV, CHD/CVD, behaviors, and accidents.

Alternative attributions. There were two patterns that emerged among the alternative attributions. One was the recognition of people's ways of coping and/or responding to racism or sexism, and the second was to acknowledge that racist or sexist conditions in society may contribute to stress and health problems. 
It was common for authors to recognize coping with stress as a factor that contributes to smoking behaviors, specifically. The following quotes illustrate some of the ways authors acknowledged coping behaviors:

Smoking may represent a coping behavior that mitigates the harmful psychological impact of a stressful environment. ${ }^{2}$

One speculation is that the lives of Black women in their $20 \mathrm{~s}$ and $30 \mathrm{~s}$ are more stressful than those of their White counterparts and their greater tendency to smoke may be, in part, a response to this stress. The sources of this stress, the stress itself, or the physical toll taken by actively coping with stress over a prolonged period may contribute to the excess disease, disability, and death of young and middle-aged adult Black women. ${ }^{2}$

The author of these quotes recognizes that Black and white women experience different levels of stress over long periods of time. The next quotes recognize that the stress of the situation may contribute to health problems:

Job strain was somewhat more consistently associated with pre-term delivery among Black women, supporting the hypothesis that Black women may be at higher risk for this pregnancy outcome partially as a result of their increased exposure and response to stress. ${ }^{6}$

The results corroborate findings from other studies examining the consequences of partner abuse, including repetition of the partner's assault, partner's betrayal of care, and the woman's feelings of isolation. ${ }^{8}$ 
A woman's exposure as a young child to the effects of poverty or racial discrimination could adversely affect birth weight in the next generation. ${ }^{13}$

The previous examples recognize the impact of prolonged stress, repeated occurrences of abuse, and increased exposure to stress on health behaviors and health outcomes. In a few cases, authors recognized that behaviors that may be considered healthy may have negative consequences for some women:

Less obvious, however, is the indirect health threat that results from women's reluctance to negotiate condom use because of fear of domestic violence. Such fear may reduce the likelihood of women's using condoms and thus contribute to increased transmission of sexually transmitted diseases, including HIV infection. ${ }^{8}$

Finally, a significant number of the African American women presenting with late-stage disease were reluctant to seek medical treatment for cancer because of their fears about how the disease would impact on their relationships with the men in their lives. ${ }^{12}$

These examples speak specifically to the difficulties women have negotiating present and future threats to their health. In the first example, condom use may be considered a way of protecting herself from future mortality, but is a potential risk to her current health status. The immediacy of the situation dictates the behavior. In 
the second example, the risk of losing a partner to treat a disease that may not be cured by the procedure is paramount to the women. These women may be more likely to see other women die from breast cancer despite treatment than they do women who are in a loving relationship with a male partner. They may consider their relationship to be more important than their personal health. This also speaks to the issue of immediacy, having a partner that helps raise children or contributes economically to the family may be a greater priority in their lives.

Alternative attributions occurred least in 1995 when none of the explanations were coded as alternative (Table 5). Alternative was the least occurring attribution category in most years, however alternative attributions exceeded genetic attributions in 1993 and 1996 (Figure 8). The AJPH had the highest percentage of alternative explanations with $5 \%$ and JAMA had the lowest percentage (3\%), however there was little variance among the attributions by journal.

Among race/sex groups (Figure 6), alternative attributions occurred most often when Black males and 
females were compared with each other. The topics in which alternative attributions occurred most of ten were behaviors (Table 8). Alternative attributions accounted for $14 \%$ of the explanations for this topic. Alternative attributions accounted for none of the explanations when the topic was services and accidents.

\section{Results Specific to Research Questions}

Research question one. With what frequency do researchers employ the four types of attributions to explain health and mortality differences among Black and white women? Alternative attributions occurred more often when the study population was Black males (10\%) and Black females only ( $8 \%)$. Alternative attributions occurred more in 1996 than in any of the other years reviewed. Structural attributions were more common (47\%) than any of the other attributions. Cultural attributions were the second most common $(40 \%)$, genetic attributions were third $(8 \%)$ and alternative attributions were fourth $(5 \%)$.

Research question two. Is there any relationship between the topic of the article (subject) and attributions? The topics that had the highest percentage 
of alternative (Table 8 ) attributions was behaviors (14\%) . One of the possible reasons for this could be because most of the behavior articles were in the AJPH (95\%). The AJPH had the highest percentage of alternative attributions (Figure 7). Additionally, 25\% of the articles on behaviors were written in 1996 when alternative attributions were highest. Cancers were the topics with the second highest percentage of alternative attributions (6\%).

Research question three. Are there any changes in the attributions used over the ten year time period (1989-1998) studied? The pattern for attributions made over the ten year period for the three journals did not vary much by year (Figure 8 ). The pattern of distribution varied more for the cultural and structural attributions than genetic or alternative. Overall, there was very little variance in the percentage of alternative and genetic attributions during the ten year period of time. Structural attributions increased from about $40 \%$ in 1989 to about $50 \%$ in 1998 , and cultural attributions decreased from about $46 \%$ in 1989 to about $35 \%$ in 1998 . Alternative attributions never exceeded cultural or structural 
attributions and only exceeded genetic in 1993 and 1996. Structural attributions were usually highest, with the exception of 1990 when cultural attributions were highest of all attributions.

Research question four. Are there any differences in the attributions used by sex/race of the study population? Differences between Black females and Black males were more likely to be explained using alternative attributions (race and sex status) than among any of the other race/sex groups. Articles with Black males and females both and Black women alone had the highest percentage of alternative attributions $(10 \%$ and $8 \%$ respectively). Part of the reason for the higher percentage of alternative attributions among these study populations could be due to the fact that $22 \%$ of the articles with Black women and $25 \%$ of the articles for Black women and men as the study population were in behaviors topics, such as substance use/abuse, obesity, and exercise (Table 9). While a majority of the articles for this study came from the AJPH, an even larger percentage of the articles with Black males and females as the study population were from the AJPH (Table 4) which 
also had the highest occurrence of alternative attributions of all the journals. .

Cultural attributions were more likely to occur among study populations with more ethnic and minority diversity (Figure 6). The Black/others, males and females group had the highest percentage of cultural attributions (53\%) and Black/white female comparisons had the lowest percentage of cultural attributions (36\%). The highest percentage of structural attributions occurred within the Black/other females population ( $54 \%$ ) and the lowest percentage occurred when the study population was Black/other males and females (39\%). Genetic attributions were more likely to occur when comparisons were made between Blacks and whites.

Research question five. Are there any differences in the attributions used by journal? As stated earlier in this section, the AJPH had the highest percentage of alternative and structure attributions (Figure 7). JAMA had the highest percentage of genetic attributions and the NEJM had the highest percentage of cultural attributions. Differences in type of attribution are probably due to the focus of each journals. Both the 
NEJM and the JAMA are focused on scientific medical analysis. The AJPH is more focused on the relationship between public policy and health. While the focus on scientific medical analysis among the NEJM and JAMA is understandable to some extent, their failure to adequately explain differences in health and mortality, between Blacks and whites in particular, should lead to the inclusion of more research that examines the relationship between racism and health and mortality outcomes. 


\section{CHAPTER V \\ DISCUSSION AND CONCLUSION}

In most of the examples provided in the previous section, the problems and solutions, to health and mortality outcomes, lie within the individual's realm. An individual's unhealthy behaviors are caused by their "cultural" beliefs, failure to utilize available services, and lack of compliance with recommended treatment. The overall question of "why" is not answered. Why don't individuals comply? And why don't they utilize services?

These researchers assume that the world is open and that all individuals have to do is to make choices.

The statements and explanations given for different health and mortality outcomes among Blacks and whites and males and females do not reflect empathy for the conditions in which oppressed people are living. In most cases, the researchers make no attempt to understand "why" these conditions exist, and they do not address broader issues within society that create these conditions and limit choices. In addition, there is no recognition of the ways that racism and sexism have shaped social policy, health care, and behaviors. 
While many of the researchers recognize the importance of structural inequality in creating different health and mortality outcomes among different groups of people and that differences in jobs, wages, and education exist, they fail to acknowledge the role of racism and sexism in contributing to these differences. They speak as if these differences just exist without any structural mechanisms creating them.

The goal of this research was to explore the attributions made about Black women's health and mortality. I looked at three journals, JAMA, AJPH, and NEJM over a ten year period of time (1989-1998) using models of health and mortality influenced by Kreiger and Bassett (1993) and Hummer (1996). My findings have demonstrated that researchers are more likely to use cultural and structural attributions and least likely to employ genetic or alternative attributions to explain the differences in health and mortality between Black women and other groups. For example, overall, genetic attributions occurred $12 \%$ of the time, cultural attributions occurred $42 \%$ of the time, structural 
attributions occurred $43 \%$ of the time and alternative attributions occurred $3 \%$ of the time (Table 6).

Genetic attributions occurred more frequently than alternative attributions, but were uncommon in relation to other attributions. While alternative attributions are considered in some of the research that explores Black women's health and mortality, they are overall rarely employed. Research that considers alternative attributions in order to understand health and mortality differences offers the potential to move the discussion of health outcomes beyond the individual and to explore racist and sexist structures, practices, and policies as heath determinants.

Based on my review of literature, I expected there would be some relationship between the debates within the fields of medical and public health research and the actual research being conducted. Many of the debates I reviewed were critical of existing research for not considering race, sex, and class inequality and the context in which oppressed people live as a primary determinate of health and mortality. However, I found that there was no increase in the use of alternative 
explanations over the ten year period of time I studied. Additionally, with the decreasing acceptance of genetic and biological arguments for health differences I expected there to be less emphasis on race as a genetic/biological category. The dichotomy between Blacks and whites was over-emphasized in many of the articles I reviewed. I expected the researchers to acknowledge race, but to acknowledge it as a socially constructed category that is used to support racist policies and practices. These policies and practices, in turn, create social conditions that influence health and mortality outcomes differently for Blacks and whites.

This study supports theories presented by some critics of medical research. These critics argue that explanations for different health and mortality outcomes among groups focus too exclusively on cultural and structural attributions and do not acknowledge the direct effects of racism and sexism or the context in which oppressed groups must live. Neglect of racism and sexism by researchers has inhibited understanding of the causes of differences in health and mortality among different racial/ethnic groups. These articles inform health 
policy and practices as well as popular media. They shape medical doctors' understanding of health problems and influence how doctors treat patients.

My research was limited in many ways. There are very few studies of medical journals that have used content analysis and even fewer guidelines for conducting such research. This is especially important when one considers the fact that medical practitioners spend at least four hours a week reading these articles in medical journals (Saint and colleagues 2000) I was on my own in the development of coding criteria, tools, and analysis. As a graduate student with limited time and resources, I was unable to adequately pretest my coding sheet or check for inter-coder reliability. In addition, my research was limited by the amount of content I was able to analyze. I limited the analysis to specific articles in three journals over a ten year time period. 
Future research on this topic should focus on examination of more articles within more journals to provide a broader understanding of the attributions given for differences in health and mortality outcomes among various groups. There should be some attempt to use journals that approach the topic of health in a variety of ways. Journals could include those that approach health from scientific, public health, health policy, services, sociological, psychological, and epidemiological perspectives. In addition, using qualitative methods for collecting information is necessary, but analysis of the data can also be done using quantitative methods. This would allow the researcher to provide some more complex analysis of the data collected as well as combine variables to increase our understanding of the relationship between study populations, time of study, topics, and attributions. 
Table 1. 1996 Death Rates for the 10 Leading Causes of Death in the U.S. Black and White Women, 45-64 Years

\begin{tabular}{lcc}
\hline \multicolumn{1}{c}{ Cause } & White Women & Black Women \\
\hline Malignant Neoplasms (Cancer) & 96.0 & 277.6 \\
Diseases of the Heart & 22.9 & 241.1 \\
Chronic Obstructive Pulmonary & 21.1 & 21.8 \\
Disease & & \\
Cerebrovascular Disease & 17.1 & 56.1 \\
$\begin{array}{l}\text { Diabetes Mellitus } \\
\text { Accidents and Adverse Effects }\end{array}$ & 9.3 & 54.7 \\
$\begin{array}{l}\text { Chronic Liver Disease and } \\
\text { Cirrhosis }\end{array}$ & 7.7 & 22.4 \\
$\begin{array}{l}\text { Pneumonia and Influenza } \\
\text { Suicide }\end{array}$ & 10.4 & 15.6 \\
$\begin{array}{l}\text { Septicemia (blood diseases) } \\
\text { Human Immunodeficiency }\end{array}$ & 7.4 & 14.7 \\
$\begin{array}{l}\text { Virus } \\
\text { Nephris, Nephrotic Syndrome, } \\
\text { and Nephrosis (kidney diseases) }\end{array}$ & 7.0 & NA \\
\hline & 3.6 & NA \\
\hline
\end{tabular}

Source: National Vital Statistics Report

Rates per 100,000 
Table 2. Breakdown of PubMed Search Process

\begin{tabular}{|c|c|c|c|c|c|}
\hline \multirow[b]{2}{*}{ Journal } & \multicolumn{4}{|c|}{ Search Term } & \multirow[b]{2}{*}{$\begin{array}{c}\text { Articles } \\
\text { Reviewed }\end{array}$} \\
\hline & $\begin{array}{c}\text { All } \\
\text { Articles }\end{array}$ & Black* & $\begin{array}{c}\text { Black* } \\
\text { Women }\end{array}$ & $\begin{array}{l}\text { Black" } \\
\text { Women } \\
\text { '89-'98 }\end{array}$ & \\
\hline NEJM & $\begin{array}{c}40336 \\
(43.69 \%)\end{array}$ & $\begin{array}{c}223 \\
(18.68 \%)\end{array}$ & $\begin{array}{c}44 \\
(14.52 \%)\end{array}$ & $\begin{array}{c}30 \\
(14.78 \%)\end{array}$ & 26 \\
\hline AJPH & $\begin{array}{c}8394 \\
(9.09 \%)\end{array}$ & $\begin{array}{c}575 \\
(48.16 \%)\end{array}$ & $\begin{array}{c}167 \\
(55.12 \%)\end{array}$ & $\begin{array}{c}115 \\
(56.65 \%)\end{array}$ & 81 \\
\hline JAMA & $\begin{array}{c}43587 \\
(47.21 \%)\end{array}$ & $\begin{array}{c}396 \\
(33.17 \%)\end{array}$ & $\begin{array}{c}92 \\
(30.36 \%)\end{array}$ & $\begin{array}{c}58 \\
(28.57 \%)\end{array}$ & 28 \\
\hline Total & $\begin{array}{c}92317 \\
(100 \%)\end{array}$ & $\begin{array}{c}1194 \\
(100 \%)\end{array}$ & $\begin{array}{c}303 \\
(100 \%)\end{array}$ & $\begin{array}{c}203 \\
(100 \%)\end{array}$ & 135 \\
\hline
\end{tabular}

* Results were the same when using African American as the search term.

PubMed is a search system that includes citations provided by the National Center for Biotechnology Information and the National Library of Medicine. Publishers supply the citations prior to or at the time of publication. Not all articles published within each journal is supplied by the publishers. 
Table 3. Journal Articles by Topic (NEJM, AJPH, and JAMA 19891998)

\begin{tabular}{|c|c|c|c|c|}
\hline \multirow[b]{2}{*}{ Topic } & \multicolumn{3}{|c|}{ Journal } & \multirow[b]{2}{*}{ Total } \\
\hline & NEJM & AJPH & JAMA & \\
\hline STD/HIV & $\begin{array}{c}7 \\
(26.92 \%)\end{array}$ & $\begin{array}{c}6 \\
(7.41 \%)\end{array}$ & $\begin{array}{c}7 \\
(25.00 \%)\end{array}$ & 20 \\
\hline Reproductive & $\begin{array}{c}8 \\
(30.77 \%)\end{array}$ & $\begin{array}{c}17 \\
(20.99 \%)\end{array}$ & $\begin{array}{c}6 \\
(21.43 \%)\end{array}$ & 31 \\
\hline CHD/CVD & $\begin{array}{c}2 \\
(7.96 \%)\end{array}$ & $\begin{array}{c}6 \\
(7.41 \%)\end{array}$ & $\begin{array}{c}5 \\
(17.86 \%)\end{array}$ & 13 \\
\hline Behaviors & $\begin{array}{c}0 \\
(0.00 \%)\end{array}$ & $\begin{array}{c}18 \\
(22.22 \%)\end{array}$ & $\begin{array}{c}1 \\
(3.57 \%)\end{array}$ & 19 \\
\hline Mortality & $\begin{array}{c}6 \\
(23.08 \%)\end{array}$ & $\begin{array}{c}3 \\
(3.70 \%)\end{array}$ & $\begin{array}{c}2 \\
(7.14 \%)\end{array}$ & 11 \\
\hline Services & $\begin{array}{c}0 \\
(0.00 \%)\end{array}$ & $\begin{array}{c}2 \\
(2.47 \%)\end{array}$ & $\begin{array}{c}3 \\
(10.71 \%)\end{array}$ & 5 \\
\hline Cancers & $\begin{array}{c}1 \\
(3.85 \%)\end{array}$ & $\begin{array}{c}15 \\
(18.52 \%)\end{array}$ & $\begin{array}{c}3 \\
(10.71 \%)\end{array}$ & 19 \\
\hline Accidents & $\begin{array}{c}1 \\
(3.85 \%)\end{array}$ & $\begin{array}{c}2 \\
(2.47 \%)\end{array}$ & $\begin{array}{c}0 \\
(0.00 \%)\end{array}$ & 3 \\
\hline Degenerative & $\begin{array}{c}1 \\
(3.85 \%)\end{array}$ & $\begin{array}{c}12 \\
(14.81 \%)\end{array}$ & $\begin{array}{c}1 \\
(3.57 \%)\end{array}$ & 14 \\
\hline Total & $\begin{array}{c}26 \\
(100 \%)\end{array}$ & $\begin{array}{c}81 \\
(100 \%)\end{array}$ & $\begin{array}{c}28 \\
(100 \%)\end{array}$ & 135 \\
\hline
\end{tabular}


Table 4. Study Population (Race/Sex) by Journal

\begin{tabular}{lccc}
\hline & \multicolumn{3}{c}{ Journal } \\
\cline { 2 - 4 } (Race) Sex & NEJM & AJPH & JAMA \\
\hline (B) F & 2 & 5 & 2 \\
& $(7.69 \%)$ & $(6.17 \%)$ & $(7.14 \%)$ \\
(B/W) F & 3 & 32 & 5 \\
& $(11.54 \%)$ & $(39.51 \%)$ & $(17.86 \%)$ \\
(B/O) F & 9 & 13 & 5 \\
& $(34.61 \%)$ & $(16.05 \%)$ & $(17.86 \%)$ \\
(B) M/F & 0 & 9 & 3 \\
& $(0.00 \%)$ & $(11.11 \%)$ & $(10.71 \%)$ \\
(B/W) M/F & 9 & 13 & 6 \\
& $(34.61 \%)$ & $(16.05 \%)$ & $(21.43 \%)$ \\
(B/O) M/F & 3 & 9 & 7 \\
Total & $(11.54 \%)$ & $(11.11 \%)$ & $(25.00 \%)$ \\
& 26 & 81 & 28 \\
\hline
\end{tabular}


Table 5. Attributions by Year, 1989-1998

\begin{tabular}{|c|c|c|c|c|c|}
\hline \multirow[b]{2}{*}{ Year } & \multicolumn{4}{|c|}{ Attribution } & \multirow[b]{2}{*}{ Total } \\
\hline & Genetic & Culture & Structure & Alternative & \\
\hline 1989 & $\begin{array}{c}2 \\
(9.09 \%)\end{array}$ & $\begin{array}{c}6 \\
(27.27 \%)\end{array}$ & $\begin{array}{c}12 \\
(54.54 \%)\end{array}$ & $\begin{array}{c}2 \\
(9.09 \%)\end{array}$ & $\begin{array}{c}22 \\
(100 \%)\end{array}$ \\
\hline 1990 & $\begin{array}{c}2 \\
(5.88 \%)\end{array}$ & $\begin{array}{c}20 \\
(58.82 \%)\end{array}$ & $\begin{array}{c}11 \\
(32.35 \%)\end{array}$ & $\begin{array}{c}1 \\
(2.94 \%)\end{array}$ & $\begin{array}{c}34 \\
(100 \%)\end{array}$ \\
\hline 1991 & $\begin{array}{c}7 \\
(9.72 \%)\end{array}$ & $\begin{array}{c}29 \\
(40.28 \%)\end{array}$ & $\begin{array}{c}31 \\
(43.05 \%)\end{array}$ & $\begin{array}{c}5 \\
(6.94 \%)\end{array}$ & $\begin{array}{c}72 \\
(100 \%)\end{array}$ \\
\hline 1992 & $\begin{array}{c}7 \\
(6.86 \%)\end{array}$ & $\begin{array}{c}44 \\
(43.14 \%)\end{array}$ & $\begin{array}{c}49 \\
(48.04 \%)\end{array}$ & $\begin{array}{c}2 \\
(1.96 \%)\end{array}$ & $\begin{array}{c}102 \\
(100 \%)\end{array}$ \\
\hline 1993 & $\begin{array}{c}2 \\
(3.12 \%)\end{array}$ & $\begin{array}{c}26 \\
(40.62 \%)\end{array}$ & $\begin{array}{c}32 \\
(50.00 \%)\end{array}$ & $\begin{array}{c}4 \\
(6.25 \%)\end{array}$ & $\begin{array}{c}64 \\
(100 \%)\end{array}$ \\
\hline 1994 & $\begin{array}{c}10 \\
(16.39 \%)\end{array}$ & $\begin{array}{c}25 \\
(39.06 \%)\end{array}$ & $\begin{array}{c}25 \\
(39.06 \%)\end{array}$ & $\begin{array}{c}1 \\
(1.64 \%)\end{array}$ & $\begin{array}{c}61 \\
(100 \%)\end{array}$ \\
\hline 1995 & $\begin{array}{c}3 \\
(6.67 \%)\end{array}$ & $\begin{array}{c}17 \\
(37.78 \%)\end{array}$ & $\begin{array}{c}25 \\
(55.55 \%)\end{array}$ & $\begin{array}{c}0 \\
(0.00 \%)\end{array}$ & $\begin{array}{c}45 \\
(100 \%)\end{array}$ \\
\hline 1996 & $\begin{array}{c}3 \\
(4.61 \%)\end{array}$ & $\begin{array}{c}25 \\
(38.46 \%)\end{array}$ & $\begin{array}{c}31 \\
(47.69 \%)\end{array}$ & $\begin{array}{c}6 \\
(9.23 \%)\end{array}$ & $\begin{array}{c}65 \\
(100 \%)\end{array}$ \\
\hline 1997 & $\begin{array}{c}7 \\
(9.59 \%)\end{array}$ & $\begin{array}{c}25 \\
(34.25 \%)\end{array}$ & $\begin{array}{c}39 \\
(53.42 \%)\end{array}$ & $\begin{array}{c}2 \\
(2.74 \%)\end{array}$ & $\begin{array}{c}73 \\
(100 \%)\end{array}$ \\
\hline 1998 & $\begin{array}{c}8 \\
(10.00 \%)\end{array}$ & $\begin{array}{c}39 \\
(36.25 \%)\end{array}$ & $\begin{array}{c}38 \\
(47.50 \%)\end{array}$ & $\begin{array}{c}5 \\
(6.25 \%)\end{array}$ & $\begin{array}{c}80 \\
(100 \%)\end{array}$ \\
\hline Total & 51 & 246 & 293 & 28 & 618 \\
\hline
\end{tabular}


Table 6. Attributions by Journal, 1989-1998

\begin{tabular}{cccccc}
\hline \hline & \multicolumn{4}{c}{ Attribution } & \\
\cline { 2 - 5 } Journal & Genetic & Culture & Structure & Alternative & Total \\
\hline \multirow{2}{*}{ NEJM } & 9 & 60 & 60 & 6 & 135 \\
& $(6.67 \%)$ & $(44.44 \%)$ & $(44.44 \%)$ & $(4.44 \%)$ & $(100 \%)$ \\
AJPH & 28 & 135 & 180 & 18 & 361 \\
& $(7.76 \%)$ & $(37.40 \%)$ & $(49.86 \%)$ & $(4.99 \%)$ & $(100 \%)$ \\
JAMA & 14 & 51 & 53 & 4 & 122 \\
& $(11.47 \%)$ & $(41.80 \%)$ & $(43.44 \%)$ & $(3.29 \%)$ & $(100 \%)$ \\
Total & 51 & 246 & 293 & 28 & 618 \\
\hline
\end{tabular}


Table 7. Attributions by Race/Sex, 1989-1998

\begin{tabular}{lccccc}
\hline \hline & \multicolumn{4}{c}{ Attribution } & \\
\cline { 2 - 5 } (Race) Sex & Genetic & Culture & Structure & Alternative & Total \\
\hline (B) F & 2 & 10 & 12 & 2 & 26 \\
& $(7.60 \%)$ & $(38.46 \%)$ & $(46.15 \%)$ & $(7.60 \%)$ & $(100 \%)$ \\
(B/W) F & 20 & 59 & 80 & 7 & 166 \\
& $(12.05 \%)$ & $(35.54 \%)$ & $(48.19 \%)$ & $(4.22 \%)$ & $(100 \%)$ \\
(B/O) F & 6 & 45 & 66 & 5 & 122 \\
& $(4.92 \%)$ & $(36.88 \%)$ & $(54.10 \%)$ & $(4.10 \%)$ & $(100 \%)$ \\
(B) M/F & 2 & 23 & 30 & 6 & 61 \\
& $(3.28 \%)$ & $(37.70 \%)$ & $(49.18 \%)$ & $(4.48 \%)$ & $(100 \%)$ \\
(B/W) M/F & 15 & 51 & 62 & 6 & 134 \\
& $(11.19 \%)$ & $(38.06 \%)$ & $(46.27 \%)$ & $(4.48 \%)$ & $(100 \%)$ \\
(B/O) M/F & 6 & 58 & 43 & 2 & 109 \\
& $(5.50 \%)$ & $(53.21 \%)$ & $(39.45 \%)$ & $(1.83 \%)$ & $(100 \%)$ \\
Total & 51 & 246 & 293 & 28 & 618 \\
\hline
\end{tabular}


Table 8

Attributions by Topic, 1989-1998

\begin{tabular}{|c|c|c|c|c|}
\hline \multirow[b]{2}{*}{ Topic } & \multicolumn{4}{|c|}{ Attribution } \\
\hline & Genetic & Culture & Structure & Alternative \\
\hline STD/HIV & $\begin{array}{c}7 \\
(13.73 \%)\end{array}$ & $\begin{array}{c}67 \\
(27.24 \%)\end{array}$ & $\begin{array}{c}38 \\
(12.97 \%)\end{array}$ & $\begin{array}{c}1 \\
(3.57 \%)\end{array}$ \\
\hline Reproductive & $\begin{array}{c}7 \\
(13.73 \%)\end{array}$ & $\begin{array}{c}40 \\
(16.26 \%)\end{array}$ & $\begin{array}{c}60 \\
(20.48 \%)\end{array}$ & $\begin{array}{c}3 \\
(10.71 \%)\end{array}$ \\
\hline CHD/CVD & $\begin{array}{c}4 \\
(7.84 \%)\end{array}$ & $\begin{array}{c}40 \\
(16.26 \%)\end{array}$ & $\begin{array}{c}25 \\
(8.53 \%)\end{array}$ & $\begin{array}{c}2 \\
(7.14 \%)\end{array}$ \\
\hline Behaviors & $\begin{array}{c}5 \\
(9.80 \%)\end{array}$ & $\begin{array}{c}30 \\
(12.20 \%)\end{array}$ & $\begin{array}{c}29 \\
(9.90 \%)\end{array}$ & $\begin{array}{c}10 \\
(35.71 \%)\end{array}$ \\
\hline Mortality & $\begin{array}{c}2 \\
(3.92 \%)\end{array}$ & $\begin{array}{c}21 \\
(8.54 \%)\end{array}$ & $\begin{array}{c}35 \\
(11.95 \%)\end{array}$ & $\begin{array}{c}3 \\
(10.71 \%)\end{array}$ \\
\hline Services & $\begin{array}{c}4 \\
(7.84 \%)\end{array}$ & $\begin{array}{c}1 \\
(0.41 \%)\end{array}$ & $\begin{array}{c}20 \\
(6.83 \%)\end{array}$ & $\begin{array}{c}0 \\
(0.00 \%)\end{array}$ \\
\hline Cancers & $\begin{array}{c}9 \\
(17.65 \%)\end{array}$ & $\begin{array}{c}22 \\
(8.94 \%)\end{array}$ & $\begin{array}{c}58 \\
(19.80 \%)\end{array}$ & $\begin{array}{c}6 \\
(21.43 \%)\end{array}$ \\
\hline Accidents & $\begin{array}{c}2 \\
(3.92 \%)\end{array}$ & $\begin{array}{c}5 \\
(2.03 \%)\end{array}$ & $\begin{array}{c}1 \\
(0.34 \%)\end{array}$ & $\begin{array}{c}0 \\
(0.00 \%)\end{array}$ \\
\hline Degenerative & $\begin{array}{c}11 \\
(21.57 \%)\end{array}$ & $\begin{array}{c}20 \\
(8.13 \%)\end{array}$ & $\begin{array}{c}27 \\
(9.22 \%)\end{array}$ & $\begin{array}{c}3 \\
(10.71 \%)\end{array}$ \\
\hline Total & $\begin{array}{c}51 \\
(100 \%) \\
\end{array}$ & $\begin{array}{c}246 \\
(100 \%) \\
\end{array}$ & $\begin{array}{c}293 \\
(100 \%) \\
\end{array}$ & $\begin{array}{c}28 \\
(100 \%) \\
\end{array}$ \\
\hline
\end{tabular}


Table 9. Article Topics by (Race) Sex, 1989-1998

\begin{tabular}{|c|c|c|c|c|c|c|}
\hline \multirow[b]{2}{*}{ Topic } & \multicolumn{6}{|c|}{ (Race) Sex } \\
\hline & $\begin{array}{c}\text { (B) } \\
\mathrm{F}\end{array}$ & $\begin{array}{c}(\mathbf{B} / \mathbf{W}) \\
\mathbf{F}\end{array}$ & $\begin{array}{c}(\mathrm{B} / \mathrm{O}) \\
\mathrm{F}\end{array}$ & $\begin{array}{l}\text { (B) } \\
M / F\end{array}$ & $\begin{array}{c}(\mathbf{B} / \mathbf{W}) \\
\mathbf{M} / \mathbf{F}\end{array}$ & $\begin{array}{c}(\mathrm{B} / \mathrm{O}) \\
\mathbf{M} / \mathbf{F}\end{array}$ \\
\hline STD/HIV & $\begin{array}{c}1 \\
(11 \%)\end{array}$ & $\begin{array}{c}0 \\
(0 \%)\end{array}$ & $\begin{array}{c}6 \\
(22 \%)\end{array}$ & $\begin{array}{c}2 \\
(17 \%)\end{array}$ & $\begin{array}{c}2 \\
(7 \%)\end{array}$ & $\begin{array}{c}9 \\
(47 \%)\end{array}$ \\
\hline Reproductive & $\begin{array}{c}3 \\
(33 \%)\end{array}$ & $\begin{array}{c}15 \\
(37 \%)\end{array}$ & $\begin{array}{c}12 \\
(44 \%)\end{array}$ & $\begin{array}{c}0 \\
(0 \%)\end{array}$ & $\begin{array}{c}0 \\
(0 \%)\end{array}$ & $\begin{array}{c}1 \\
(5 \%)\end{array}$ \\
\hline CHD/CVD & $\begin{array}{c}0 \\
(0 \%)\end{array}$ & $\begin{array}{c}2 \\
(5 \%)\end{array}$ & $\begin{array}{c}0 \\
(0 \%)\end{array}$ & $\begin{array}{c}2 \\
(17 \%)\end{array}$ & $\begin{array}{c}6 \\
(21 \%)\end{array}$ & $\begin{array}{c}3 \\
(16 \%)\end{array}$ \\
\hline Behaviors & $\begin{array}{c}2 \\
(22 \%)\end{array}$ & $\begin{array}{c}6 \\
(15 \%)\end{array}$ & $\begin{array}{c}2 \\
(5 \%)\end{array}$ & $\begin{array}{c}3 \\
(25 \%)\end{array}$ & $\begin{array}{c}4 \\
(14 \%)\end{array}$ & $\begin{array}{c}2 \\
(10 \%)\end{array}$ \\
\hline Mortality & $\begin{array}{c}0 \\
(0 \%)\end{array}$ & $\begin{array}{c}2 \\
(5 \%)\end{array}$ & $\begin{array}{c}0 \\
(0 \%)\end{array}$ & $\begin{array}{c}1 \\
(8 \%)\end{array}$ & $\begin{array}{c}7 \\
(25 \%)\end{array}$ & $\begin{array}{c}1 \\
(5 \%)\end{array}$ \\
\hline Services & $\begin{array}{c}0 \\
(0 \%)\end{array}$ & $\begin{array}{c}0 \\
(0 \%)\end{array}$ & $\begin{array}{c}0 \\
(0 \%)\end{array}$ & $\begin{array}{c}0 \\
(0 \%)\end{array}$ & $\begin{array}{c}4 \\
(14 \%)\end{array}$ & $\begin{array}{c}1 \\
(5 \%)\end{array}$ \\
\hline Cancers & $\begin{array}{c}2 \\
(22 \%)\end{array}$ & $\begin{array}{c}11 \\
(27 \%)\end{array}$ & $\begin{array}{c}5 \\
(18 \%)\end{array}$ & $\begin{array}{c}0 \\
(0 \%)\end{array}$ & $\begin{array}{c}1 \\
(3 \%)\end{array}$ & $\begin{array}{c}0 \\
(0 \%)\end{array}$ \\
\hline Accidents & $\begin{array}{c}1 \\
(11 \%)\end{array}$ & $\begin{array}{c}0 \\
(0 \%)\end{array}$ & $\begin{array}{c}1 \\
(4 \%)\end{array}$ & $\begin{array}{c}0 \\
(0 \%)\end{array}$ & $\begin{array}{c}1 \\
(3 \%)\end{array}$ & $\begin{array}{c}0 \\
(0 \%)\end{array}$ \\
\hline Degenerative & $\begin{array}{c}0 \\
(0 \%)\end{array}$ & $\begin{array}{c}4 \\
(10 \%)\end{array}$ & $\begin{array}{c}1 \\
(4 \%)\end{array}$ & $\begin{array}{c}4 \\
(33 \%)\end{array}$ & $\begin{array}{c}3 \\
(11 \%)\end{array}$ & $\begin{array}{c}2 \\
(11 \%)\end{array}$ \\
\hline Total & $\begin{array}{c}9 \\
(100 \%)\end{array}$ & $\begin{array}{c}40 \\
(100 \%)\end{array}$ & $\begin{array}{c}24 \\
(100 \%)\end{array}$ & $\begin{array}{c}12 \\
(100 \%)\end{array}$ & $\begin{array}{c}28 \\
(100 \%)\end{array}$ & $\begin{array}{c}19 \\
(100 \%)\end{array}$ \\
\hline
\end{tabular}


Figure 1. Models of Health and Mortality

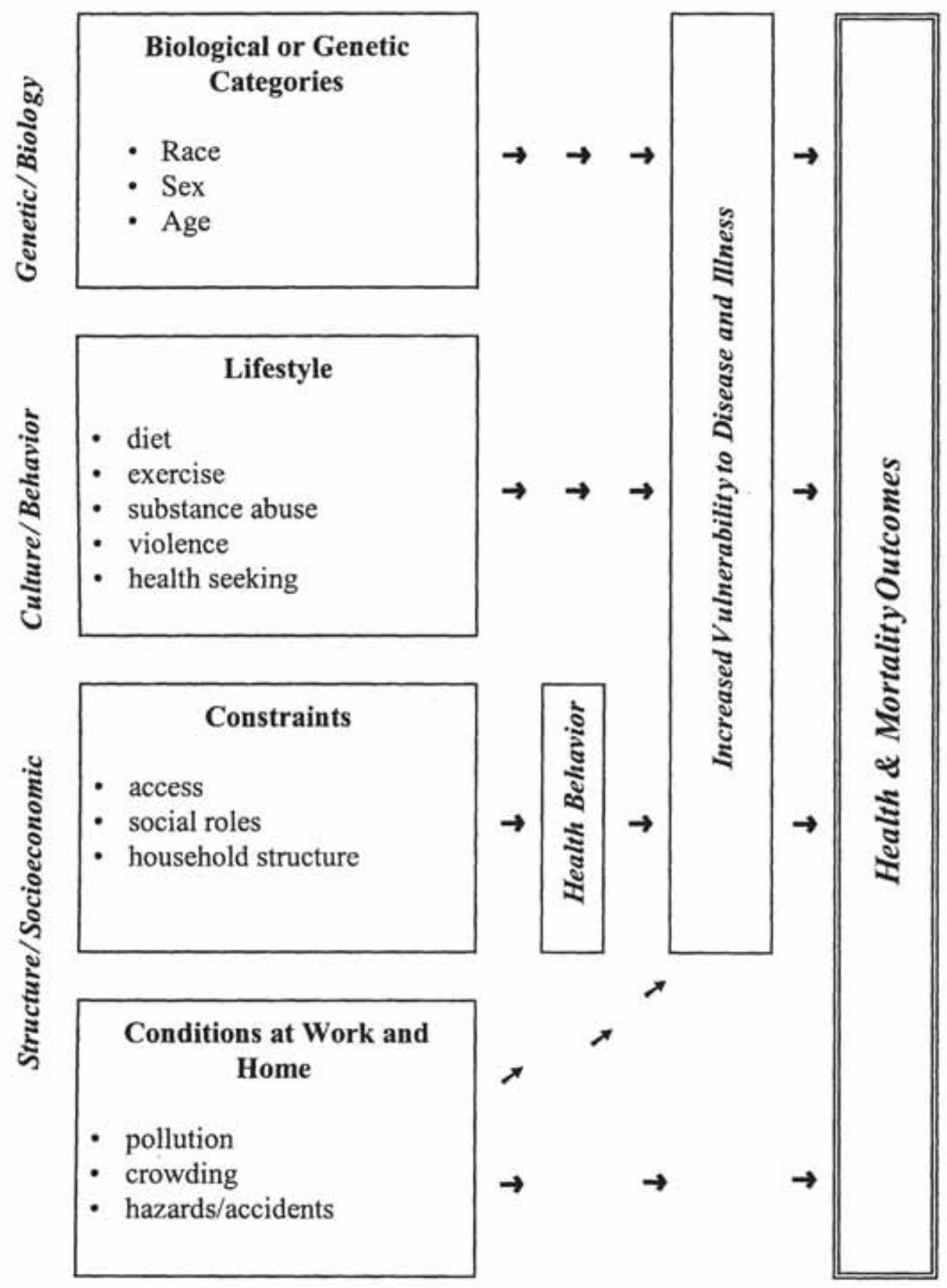


Figure 2. Alternative Model of Health and Mortality

\begin{tabular}{|c|c|} 
Primary Pathways & $\begin{array}{c}\text { Intervening } \\
\text { Factors } \\
\text { Institutional Forms of } \\
\text { Discrimination }\end{array}$ \\
Health Care \\
quality \& quantity \\
insurance coverage \\
speciality care \\
continuity \\
political representation \\
organizational participation \\
government/corporate policies \\
educational opportunities
\end{tabular}$\quad \rightarrow$

Source: Hummer, Robert A. 1996. "Black White Differences in Health and Mortality: A Review and Conceptual Model." The Sociological Quarterly 37:105-125 
Figure 3. Articles Reviewed by Journal 1989-1998

$\mathrm{N}=135$

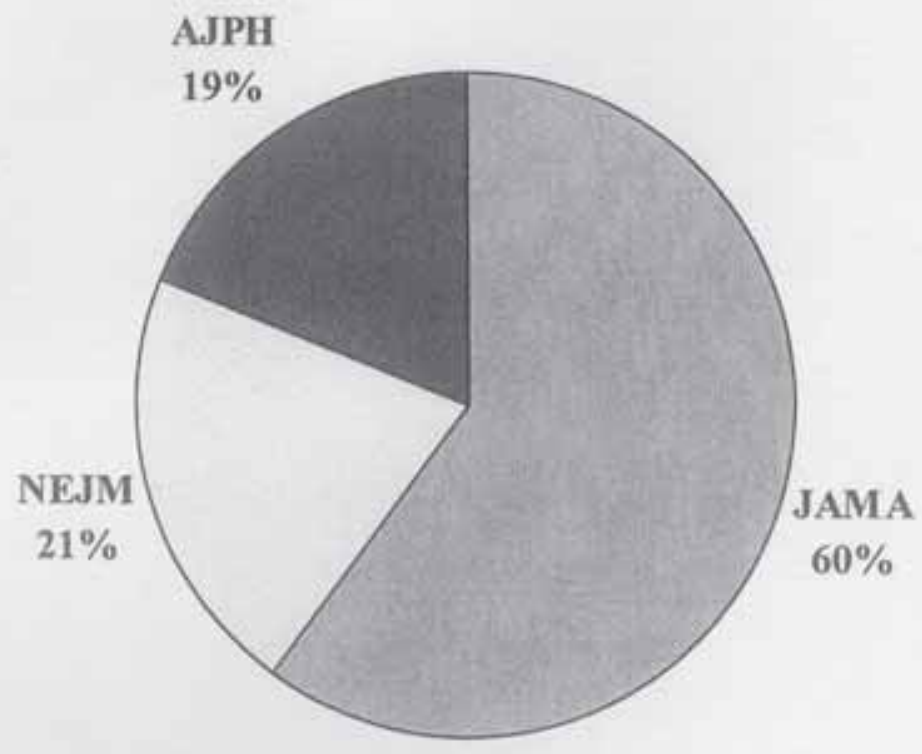


Figure 4. Articles Reviewed by Topic

NEJM, AJPH, NEJM 1989-1998

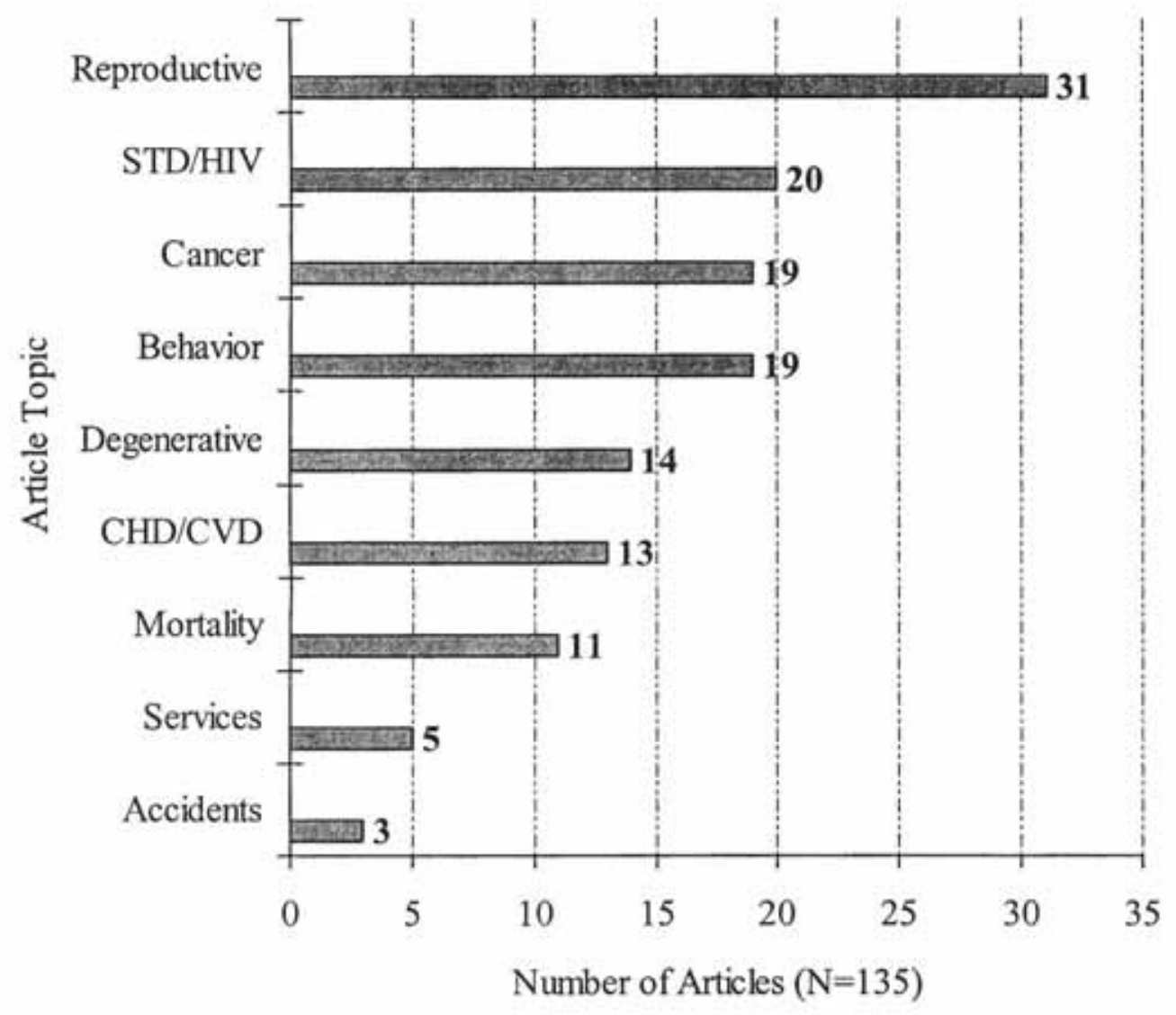


Figure 5. Articles by Race and Sex

NEJM, AJPH, JAMA 1989-1998

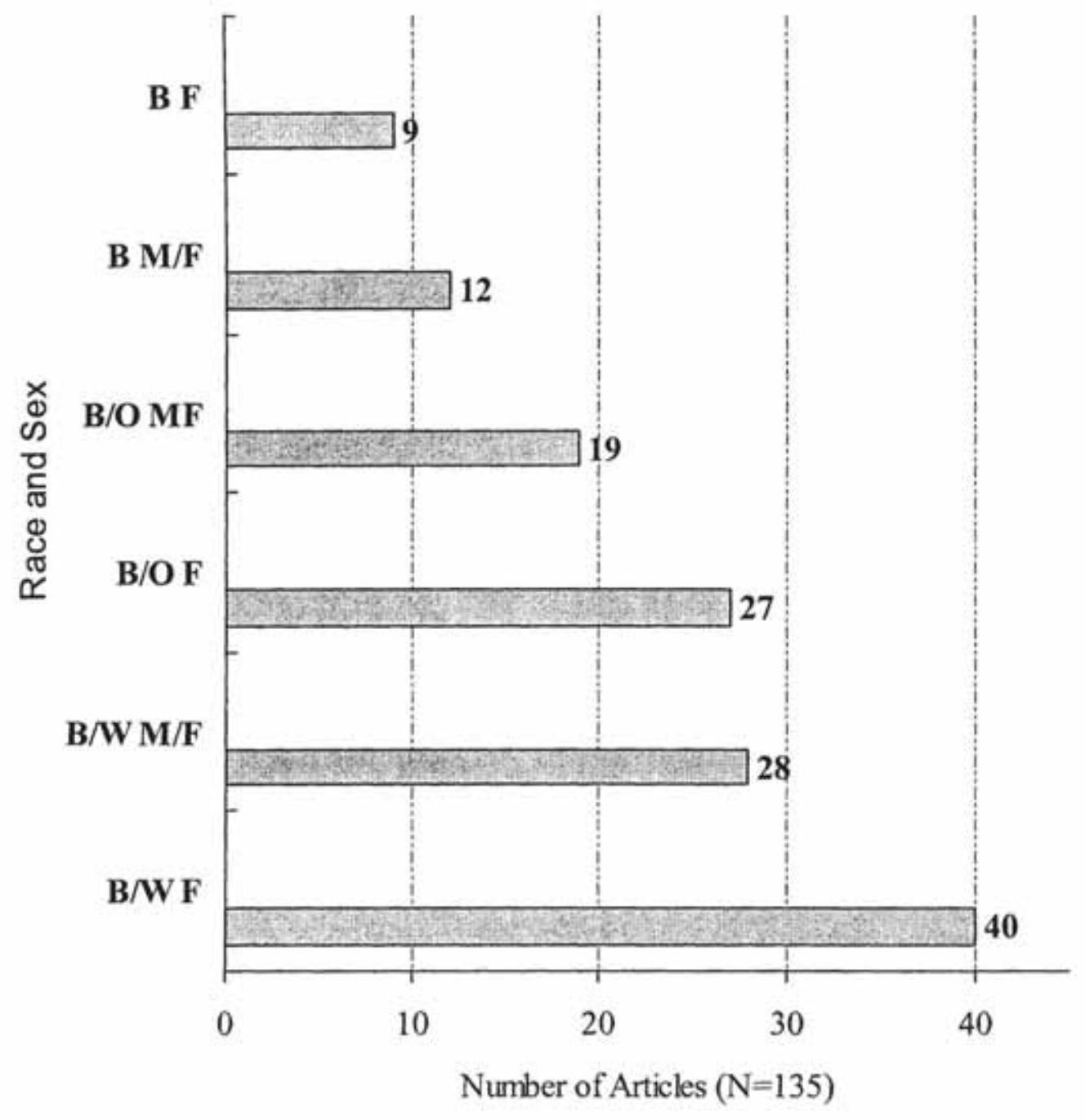


Figure 6. Attributions by Race and Sex

NEJM, AJPH, JAMA 1989-1998

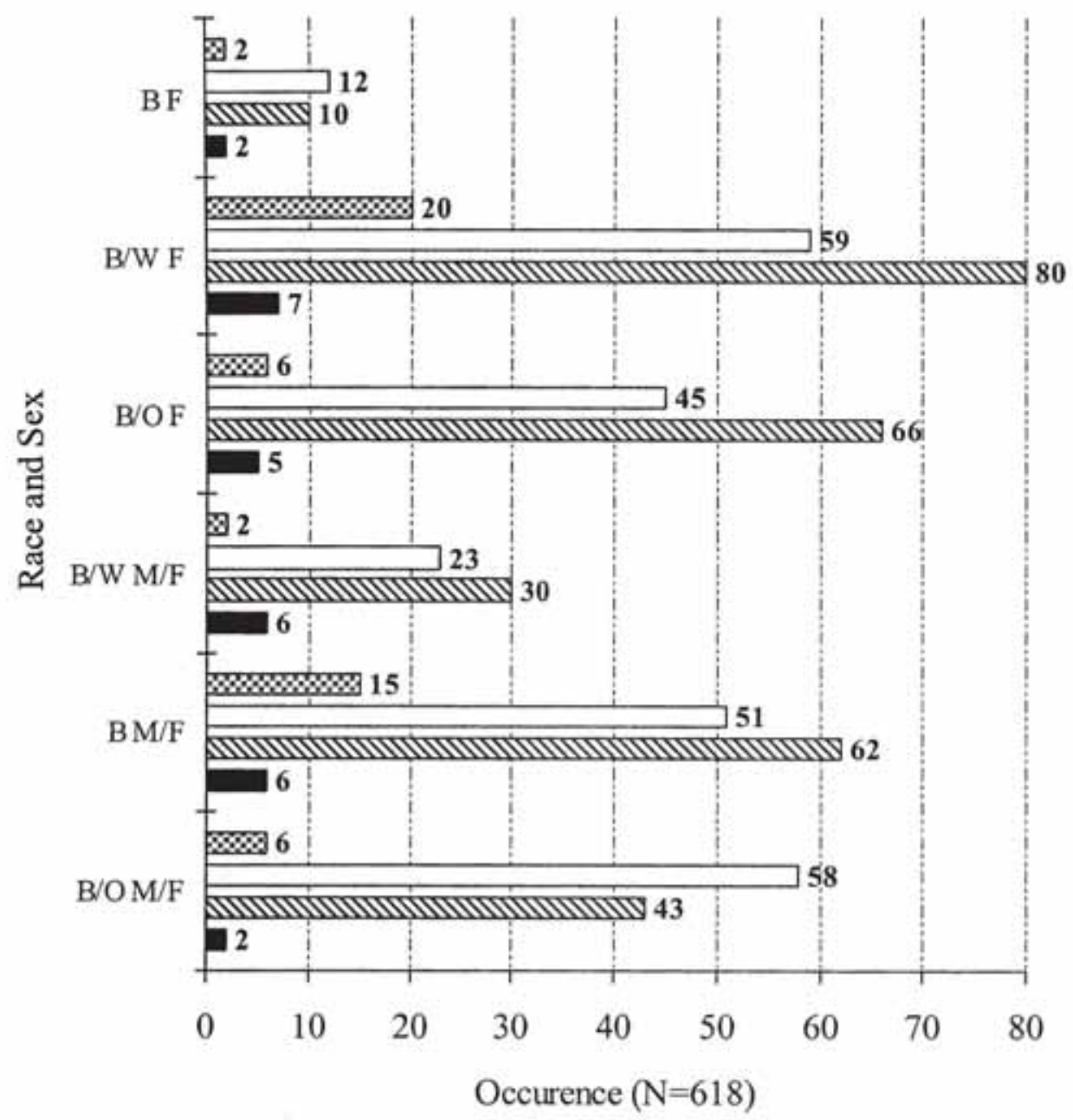

Genetic $\mathbb{\$}$ Culture $\square$ Structure : Alternative 
Figure 7. Attributions by Journals Reviewed

NEJM, AJPH, JAMA 1989-1998

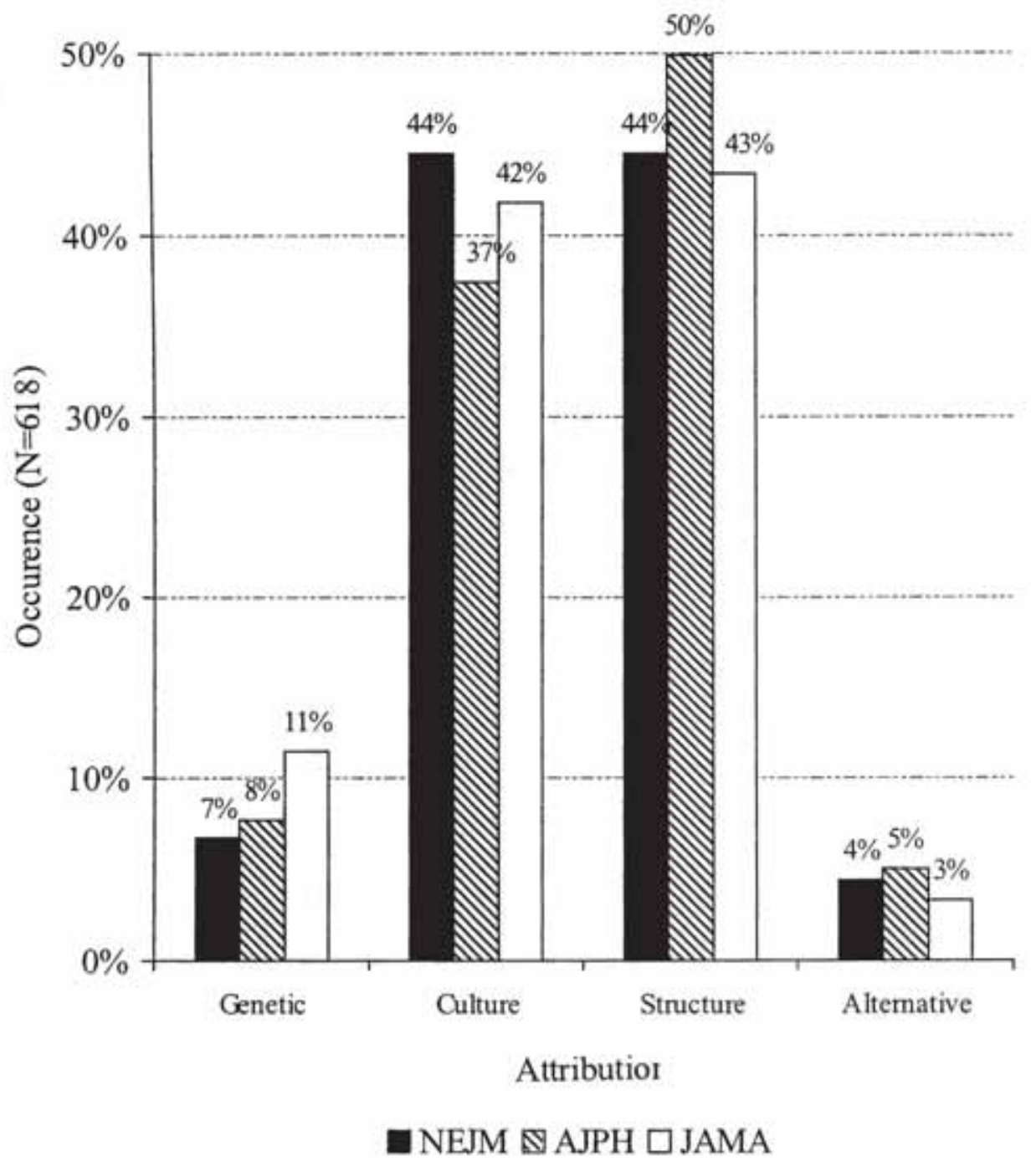


Figure 8. Attributions by Year $\mathrm{N}=618$

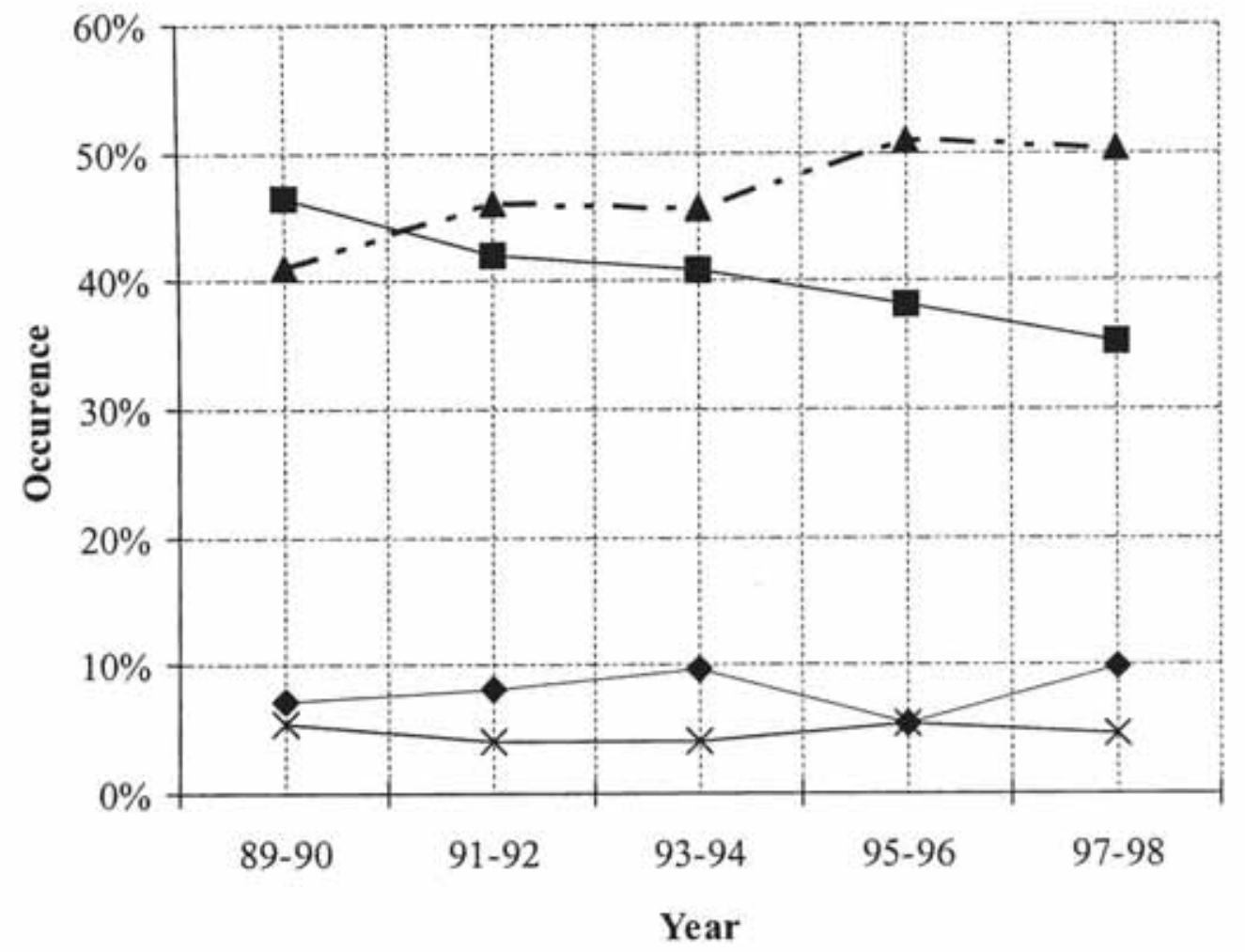

$\downarrow$ Genetic - - Culture $-\Delta-$ Structure $\rightarrow \leftarrow$ Altemative 


\section{REFERENCES}

Allen, Walter R. 1981. "The Social and Economic Statuses of Black Women in the United States." Phylon 42:26-40.

Anderson, Joan M. 1996. "Empowering Patients: Issues and Strategies." Social Science and Medicine 43:697-705.

Arfken, Cynthia 1. and Cheryl A. Houston. 1996. "Obesity in Inner-city African Americans." Ethnicity and Health 1:317-326.

Balshem, Martha. 1993. Cancer in the Community: Class and Medical Authority. Smithsonian Institution. Washington D. C.

Bennet, E. M. 1991. "Weight-loss Practices of Overweight Adults." American Journal of Clinical Nutrition 53:1519S-1521S.

Bullard, Robert. 1994. Dumping in Dixie: Race, Class, and Environmental Quality. Boulder, Colorado: Westview Press.

Cooper, R. and R. David. 1986. "The Biological Concept of Race and its Application to Public Health and Epidemiology." Journal of Health, Politics, Policy, and Law 11: 97-116.

Coveney, J. 1998. "The Government and Ethics of health Promotion: The Importance of Michele Foucault." Health Education Research 13:459468.

Crews, D. E. and J. R. Bindon. 1991. "Ethnicity as a Taxonomic Tool in Biomedical and Biosocial Research.” Ethnicity and Disease 1:42-49.

Crotty, Patricia. 1995. Good Nutrition? Fact and Fashion in Dietary Advice. Australia: Allyn and Unwin.

Cummings, Carol M. Robinson, M. Adrienne, Gretchen E. Lopez. 1993. "Perceptions of Discrimination, Psycho-social Functioning and Physical Symptoms of African-American Women." Pp. 53-67 in Wings of Gauze: Women of Color and the Experience of Health and Illness, edited by Bair, Barbara and Susan E. Cayleff. Detroit, Michigan: Wayne State University Press. 
Davis, Bridgett M. 1990. "Speaking of Grief: Today I Feel Real Low, I Hope You Understand." Pp. 219-225? in The Black Women's Health Book: Speaking for Ourselves edited by Evelyn C. White. Seattle, Washington: Seal Press.

Devine, Carol M. and Christine M. Olson. 1992. "Women's Perceptions About the Way Social Roles Promote or Constrain Personal Nutrition Care." Women and Health 9:

Domel, Suzanne B., Betty B. Alford, Hazel N. Cattlett, and Barbara E. Gench. 1992. "Weight Control for Black Women." Journal of American Dietetic Association 92:346-348.

Fee, Elizabeth and Nancy Krieger. 1994. Women's Health, Politics, and Power: Essays on Sex/Gender, Medicine, and Public Health. Amityville, New York: Baywood Publishing Company, Inc.

Fine, M., and S. M. Gordon. 1989. "Feminist Transformations of /Despite Psychology." Pp. ? in Gender and Thought: Psychological Perspectives edited by Crawford, M. and M. Gentry. New York: Springer-Verlag.

Gates, Gail and Mary McDonald. 1997 "Comparison of Dietary Risk Factors for Cardiovascular Disease in African-American and White Women." Journal of the American Dietetic Association 97:1394-1397.

Hawe, Penelope. 1998. "Making Sense of Context-level Influences on Health." Health Education Research 13:i-iii.

Hummer, Robert A. 1996. "Black - White Differences in Health and Mortality: A Review and Conceptual Model." The Sociological Quarterly 37:105125.

Kessler, Ronald C., and Harold W. Neighbors. 1986. "A New Perspective on the Relationships among Race, Social Class, and Psychological Distress." Journal of Health and Social Behavior 27:107-115.

Krieger, Nancy and Stephen Sidney. 1996. "Racial Discrimination and Blood Pressure: The CARDIA Study of Young Black and White Adults." American Journal of Public Health 86:370-1378. 
Krieger, Nancy and Mary Bassett. 1993. "The Health of Black Folk: Disease, Class, and Ideology in Science." Pp. 161-169 in The Racial Economy of Science: Toward a Democratic Future edited by Harding, Sandra. Indiana: Indiana University Press.

Kumanyika, S., D. D. Savage, A. G. Ramirez, J. Trevion Hutchinson, F. M. Adams-Campbell, and L. L. Watkins. 1989. "Beliefs about High Blood Pressure Prevention in a Survey of Blacks and Hispanics." American Journal of Preventative Medicine 1:21-26.

LeClere, Felicia C., Richard G. Rogers, Kimberly Peters. 1998. "Neighborhood Social Context and Racial Differences in Women's Heart Disease Mortality." Journal of Health and Social Behavior 39:93-107.

Mohai, Paul and Bunyan Bryant. 1992. Race and the Incidence of Environmental Hazards: A Time for Discourse. Boulder, Colorado: Westview Press.

National Vital Statistics Report. 1998. "1996 Death Rates: U. S. Black and White Women age 45-64." National Vital Statistics Report 47: November 10, 1998.

Saint, S., P.A. Christakis, S. Saha, J.G. Elmore, D.E. Welsh, P. Baker, and T.D. Koepsell. 2000. "Journal Reading Habits of Internists." Journal of General Internal Medicine 12:881-884.

Scott, Kesho Yvonne 1991. The Habit of Surviving: Black Women's Strategies for Life. New Brunswick, New Jersey: Rutgers University Press.

Shy, Carl. 1997. "The Failure of Academic Epidemiology Witness for the Prosecution." American Journal of Epidemiology 145:479-484.

Simon, Robin. 1997. "The Meanings Individuals attach to Role Identities and their Implications for Mental Health." Journal of Health and Social Behavior 38:256-274.

Thoits, Peggy. 1999. "Self, Identity, Stress, and Mental Health." Pages 321344 in Handbook of the Sociology of Mental Health. Edited by Carol Anenshensel and Jo C. Phelan. NY: Kluwer Academic/ Plenum Publishers. 
Thompson, Becky W. 1994. A Hunger So Wide and So Deep: A Multiracial View of Women's Eating Problems. Minneapolis, Minnesota: University of Minnesota Press.

Townes, Emilie M. 1998. Breaking the Fine Rain of Death: African American Health Issues and a Womanist Ethic of Care. NY: The Continuum Publishing Company.

Turrell, Gavin. 1998. "Determinants of Healthy Food Choice in a PopulationBased Sample." American Journal of Health Behavior 22:342-357.

Williams, David R. and Chiquita Collins. 1995. "US Socioeconomic and Racial Differences in Health: Patterns and Explanation." Annual Review of Sociology 21:349-386.

Zola, Irving Kenneth. 1983. Socio-medical Inquiries: Recollections, Reflections, and Reconsiderations. Philadelphia, Pennsylvania: Temple University Press. 


\section{APPENDIX A CODING CATEGORIES}

\section{Examples of Genetic/Biological Attributions}

body weight

anatomy

physical sensitivity

availability of compatible

organs

familial factors metabolic

events height

bone mass

biological variables

genetic factors in virus

predisposition

physical maturity race

age

drug interactions

subclinical cognitive defects

hormones

intracellular factors

\section{Examples of Cultural/Behavioral Attributions}

\section{immunization}

nutritional deficiencies

duration of sexual activity

violence

physical inactivity intravenous drug use

high crime

health seeking behavior

smoking

health care utilization compliance

marital status

high risk sexual behavior

drug/alcohol use

personal hygiene

\section{Examples of Structural/Socioeconomic Attributions}

\author{
psychological trauma \\ social isolation \\ social support \\ lack of insurance \\ class status \\ domestic violence \\ dilapidated housing
}

\author{
family dysfunction \\ resources \\ stress \\ physician neglect \\ environmental factors \\ poverty \\ diagnostic criteria bias
}

social networks

education

access

flexibility of work site

limited choices

psycho social factors

sense of control

\section{Examples of Alternative Attributions}

prolonged social distress

psychological trauma sense of control over health

determinates

lack of confidence in

medical system

faith in alternative treatments

and prayer

social injustice resistance to preventative practices

resisting treatment

coping with hassles

physical and emotional stress

attitudes toward

interventionists

living with high levels of risk internalized responses to

oppression

sex for survival

coping with social

discrimination

fears about the impact of

treatment

stress associated with racism

lifetime exposure to poverty

and racism 
APPENDIX B

CODING SHEET

\begin{tabular}{|c|c|c|c|}
\hline \multicolumn{2}{|l|}{ Journal } & \multicolumn{2}{|l|}{ Date } \\
\hline \multicolumn{2}{|l|}{ Article Title } & \multirow{2}{*}{\multicolumn{2}{|c|}{ Pages }} \\
\hline Author(s) & & & \\
\hline Population & Main Finding & & \\
\hline Genetic & Cultural & Structural & Alternative \\
\hline \multicolumn{4}{|l|}{ Examples: } \\
\hline
\end{tabular}




\section{APPENDIX C NOTES}

1. Cabral, H. et al (1990) "Foreign-Born and US-Born Black Women: Differences in Health Behaviors and Birth Outcomes.” AJPA 80:70-72.

2. Romano, P. S. et al. (1991) "Smoking, Social Support, and Hassles in an Urban African-American Community.” AJPA 81:1415-1422.

3. Kogan, M. D. et al. (1994) "Racial Disparities in Reported Prenatal Care Advice from Health Care Providers." AJPH 84:82-88.

4. English, P. B. et al. (1994) "Black-White Differences in Serum Cotinine Levels among Pregnant Women and Subsequent Effects on Infant Birthweight." AJPH 84:1439-1443.

5. Grisso, J. A. et al. (1996) "Injuries among Inner-City Minority Women: A Population-Based Study.” AJPH 86:67-70.

6. Brett, K. M. (1997) "Employment, Job Strain, and Preterm Delivery among Women in North Carolina." AJPH 87:199-204.

7. Shiono, P. H. et al. (1997) "Ethnic Differences in Birthweight: The Role of Lifestyle and Other Factors." AJPH 87:787-793.

8. Wingood, G. M. et al. (1997) "The Effects of an Abusive Primary Partner on the Condom Use and Sexual Negotiation Practices of African-American Women. AJPH 87:1016-1018.

9. Tielsch, J. M. et al. (1991) "Racial Variations in the Prevalence of Primary Open-angle glaucoma. The Baltimore Eye Survey." JAMA 266:369374.

10. Siegel, D. et al. (1992) "Prevalence and Correlates of Herpes Simplex Infections." JAMA 268:1702-1708.

11. Ayanian, J. Z. (1993) "Racial Differences in the Use of Revascularization Procedures After Coronary Angiography.” JAMA 269:2642-2646. 
12. Lannin, D. R. (1998) "Influence of Socioeconomic and Cultural Factors on Racial Difference in Late-Stage Presentation of Breast Cancer." JAMA 279:1801-1807.

13. David, R. J. and J. W. Collins (1997) "Differing Birth Weigh Among Infants of U. S. - Born Blacks, African - Born Blacks, and U. S. - Born Whites." NEJM 337:1209-1214.

14. Guralnik, J. M. et al. (1993) "Educational Status and Active Life Expectancy among Older Blacks and Whites.” NEJM 329:110-116. 


\section{APPENDIX D TOPIC CATEGORIES}

STD/HIV: HIV/AIDS, gonorrhea, syphilis, herpes, STD's (general)

Reproductive: breast feeding, low birth weight, pregnancy (general), postpartum depression, inter-pregnancy intervals, preeclampsia, cesarean

CHD/CVD: cerebrovascular disease, coronary heart disease

Behaviors: smoking, weight, health behavior (general), obesity, vaccination, dieting, use of health care, drug use, condom use

Mortality: general mortality rates, obstetrical pulmonary embolism, homicide

Services: barriers to services, rates of surgical treatments, procedures, transplants, treatments for kidney disease

Cancers: breast cancer, cancer (general), cervical cancer

Accidents: hip fracture, injuries

Degenerative: hypertension, high cholesterol, disability, bacterial infections, hip replacement, glaucoma, osteoporosis, active life expectancy 